\title{
Structural and functional consequences of switching carboxy terminal domains in mouse CD200 receptors
}

\author{
Ismat Khatri, Ivo Boudakov, Brent Lamptey, Adriana Taseva, Karrie Wong, Anna Podnos, \\ Reginald M. Gorczynski
}

Transplant Research Division, Toronto General Hospital, University Health Network, Toronto, Canada;

*Corresponding Author: ismat.khatri@utoronto.ca

Received 20 September 2012; revised 20 October 2012; accepted 19 November 2012

\begin{abstract}
CD200:CD200R interactions regulate immune responses. Since CD200Rs show extensive homology in their extracellular region, generating anti-CD200R specific antibodies is a challenge. We report below on the generation of mAbs specific for murine $(\mathrm{m}) \mathrm{R} 1 / \mathrm{R} 2$ and evidence that $\mathrm{mR2}$ is expressed on the cell surface in the absence of the adaptor protein Dap12. Despite homology between $m R 1$ and $m R 4$, the unexpected reduction in the molecular mass (i.e. $90 \mathrm{kDa}$ vs $48 \mathrm{kDa}$ ) between the two receptors suggested that the $\mathrm{TM}$ and cytoplasmic region of $\mathrm{mR4}$ regulated glycosylation. Substitution of the TM and cytoplasmic region of $m R 1$ and $m R 2$ with that of $m R 4$ reduced glycosylation of the chimeric receptors $m R_{1} r_{4}$ and $m R_{2} r_{4}$ implying that these regions regulated the glycosylation of mCD200Rs. In activation experiments, phosphorylation of Dap12 following interaction with CD200 occurred on cells expressing mR2V5 but not mR4V5. Similar experiments with the chimeric receptors $m R_{1} r_{2}$ and $\mathrm{mR}_{1} \mathrm{r}_{4}$ also produced phosphorylation of Dap12. Our data suggest that the TM and cytoplasmic region of $\mathrm{mCD} 200 \mathrm{Rs}$ dictate their state of glycosylation and provide further evidence that both mCD200R1 and mCD200R2 bind CD200 as ligand with functional consequences for downstream signaling.
\end{abstract}

Keywords: CD200 Binding; Dap12 Phosphorylation; Domain Switching; Glycosylation; Mabs to mR2

\section{INTRODUCTION}

CD200 and CD200R are type-I transmembrane proteins of the Ig superfamily, that are highly conserved during evolution. Importantly, while the CD200 gene exists as a single copy, multiple copies of CD200R exist in the rodent and human genome [1-3]. Data from a number of independent groups clearly indicates a role for CD200 interaction with its receptor(s), CD200R (1-5 in mouse), in the regulation of a variety of inflammatory and immunological responses. General agreement exists concerning the effect of CD200:CD200R1 interactions, with direct suppression of macrophage/dendritic cell activation and suppression of inflammation and immune responses [1,3-8]. However, significant controversy remains concerning the ligand binding of alternate receptors CD200R2-R5 (mR2-mR5) and it has been suggested that the physiological ligand(s) for these receptors remain unknown $[1,9,10]$. We have suggested that CD200 does indeed signal mR2-mR5 directly, as determined both by altered binding to, and phosphorylation of Dap12 [11], and by monitoring biological responses occurring in vitro following addition of $\mathrm{CD} 200 \mathrm{Fc}$ in the presence of a blocking R1 peptide, or using activating anti-(R2-R4) antibodies themselves $[12,13]$.

Primary sequence comparison of $\mathrm{mR} 1$ with the alternate receptors $\mathrm{mR} 2-\mathrm{mR} 4$ showed that $\mathrm{mR} 2, \mathrm{mR} 3$ and $\mathrm{mR} 4$ shared $84 \%, 39 \%$ and $85 \%$ identity with $\mathrm{mR} 1$. The transmembrane (TM) region of $\mathrm{mR} 2-\mathrm{mR} 4$, contains a lysine residue known to be an important "docking site" for adaptor proteins. Each alternate receptor bears a short 15 amino acid cytoplasmic tail that is highly related in sequence but nevertheless not identical between the different receptors. In contrast, mR1 has a long 67 amino acid cytoplasmic tail, with 3 conserved tyrosine residues. One of these residues is contained within an NPXY sequence motif which upon ligand binding is phosphorylated and subsequently binds to Dok1 and Dok2 adaptor proteins. Thus signaling via alternate receptors involves a Dap12 pathway, which is not implicated following CD 200:mR1 interaction [14-16].

Using C-terminally tagged $\mathrm{mR} 4$ and $\mathrm{mR} 3$ isoforms, several studies including our own $[2,11]$ show that Dap12 associates with alternate receptors $\mathrm{mR} 3$ and $\mathrm{mR} 4$ and that association of Dap12 with mR4 is contingent upon engagement with CD200Fc. Such studies are lack- 
ing for receptor $\mathrm{mR} 2$.

One unusual feature of the CD200Rs is the high content of potential $\mathrm{N}$-linked glycosylation sites, with $\mathrm{mR} 1$ $\mathrm{mR} 4$ containing 10, 6, 5 and $9 \mathrm{~N}$ glycans respectively. The change in apparent molecular mass of mR1 observed following removal of $\mathrm{N}$-linked sugars by PNGase $\mathrm{F}$ treatment from $\sim 90 \mathrm{kDa}$ to $\sim 25 \mathrm{kDa}$, indicates a content of around $70 \%$ by weight of carbohydrates. This is very high for N-linked carbohydrates and is more typical of O-linked sugars found in mucins [17]. To date, there has been no direct evidence for the involvement of N-linked oligosaccharides in the structure and function of CD200 receptors. However, both mutagenesis data [18] and a comparison to similar IgSF interactions [19], suggest that CD200-CD200R interactions are mediated by the protein not carbohydrate domains. It remains possible that the carbohydrate moiety is important in preventing non-specific protein-protein interactions thus preserving the membrane orientation of the CD200Rs. The possibility that multiple CD200Rs are co-expressed on individual cells constitutively or following immune induction, and the potential functional consequences this might have, remains unexplored. The potential of $\mathrm{mR} 1$ and alternate receptors $\mathrm{mR} 2-\mathrm{mR} 4$ to homo/hetero dimerize when coexpressed has also not been investigated.

Commercially available antibodies for $\mathrm{mR} 1$ have been used by investigators to study the surface expression of $\mathrm{mR} 1$ and also to study the interaction of $\mathrm{mR} 1$ with its ligand CD200. Since $\mathrm{mR} 1$ and $\mathrm{mR} 2$ share over $84 \%$ amino acid homology in their extracellular region, generating anti-mR2 specific antibodies has been a great challenge and commercial antibodies specific to $\mathrm{mR} 2$ are non-existent. Furthermore, the available anti-mR1 antibodies have not been thoroughly investigated for their ability to discriminate between $\mathrm{mR} 1$ and alternate CD200Rs.

In the present study, we have generated monoclonal antibodies to $\mathrm{mR} 1$ and $\mathrm{mR} 2$ and characterized them extensively for their specificity. The glycosylation state of the CD200Rs, and the effect of switching carboxy terminal domains between the receptors on CD200R structure and interaction with CD200 were also explored using anti-R1 and anti-R2 specific antibodies.

\section{MATERIALS AND METHODS}

\subsection{Cloning and Expression of CD200R-FC Fusion Proteins in CHOK Cells}

The extracellular (i.e. $\mathrm{V}+\mathrm{C}$ ) regions of $\mathrm{mCD} 200$ receptors, mR1, mR2, mR3 and mR4 were isolated by PCR from cDNA purified from mouse bone marrow cells and the sequence confirmed. Fc fusion proteins were generated by inserting the extracellular region of the four mCD200 receptor isoforms into a Not1/Age1 digested pIRESneo3 expression vector encoding the Fc domain of mouse IgG2a (mutated in the $\mathrm{CH} 2$ domain to inhibit binding to FcRs).

Transient transfections were performed in $\mathrm{CHOK} / \mathrm{Hek}$ 93 cells in serum free medium using lipofectamine 2000. $24 \mathrm{~h}$ post transfection, supernatants and cell lysates were analyzed by SDS/PAGE and western gels using antibody specific to mouse IgG2a. The mean concentration of each receptor fusion protein produced was in the range of $0.8-1 \mu \mathrm{g} / \mathrm{ml}$, as measured using purified $\mathrm{mCD} 200 \mathrm{Fc}$ as standard.

Stable cell lines of CHOK expressing high levels of $\mathrm{mR} 1 \mathrm{Fc}, \mathrm{mR} 2 \mathrm{Fc}, \mathrm{mR} 3 \mathrm{Fc}$, and $\mathrm{mR} 4 \mathrm{Fc}$ were established from cells transfected as above. Supernatants collected from $24 \mathrm{~h}$ and $48 \mathrm{~h}$ cultures of transfected cells using G418 selection and cloning were subjected to Protein A column chromatography with protein purity confirmed by subsequent Comassie staining. Table 1 shows the predicted and measured molecular mass of the various CD200Rs and their respective fusion proteins.

\subsection{Monoclonal Antibodies to CD200R-Fusion Proteins}

Purified receptor-Fc fusion proteins were used by ImmunoPrecise Antibodies Ltd (Victoria BC, Canada) to generate monoclonal antibodies in rats. Multiple attempts to generate anti-mR3 and anti-mR4 monoclonal antibodies failed but we were successful in generating monoclonals specific to $\mathrm{mR} 2$. Purified $\mathrm{mR} 1$ his protein was used to generate anti-mR1 monoclonals.

\subsection{Screening of Anti-CD200R Monoclonals}

The anti-mR1 monoclonal used throughout (2A10) was screened by ELISA, FACS and western blots. The detection antigen in ELISA was pure $\mathrm{mR} 1$ his protein whereas FACS was carried out using Hek293 cells stably expressing $\mathrm{mR} 1$. In western blot experiments pure $\mathrm{mR} 1$ his protein as well as cell lysates of $\mathrm{mR} 1$ cells were used for detection. 2A10 was also assessed for its ability to immunoprecipitate $\mathrm{mR} 1$ from cell lysates of $\mathrm{mR} 1$ transfected cells.

A sandwich ELISA was developed and used to screen for $\mathrm{mR} 2$ specific hybridomas. Purified anti-IgG2aFc antibody (Sigma Aldrich) was used as capture to bind pure $\mathrm{mR} 2 \mathrm{Fc}$, followed by incubation with the hybridoma supernatants expressing reactive anti-CD200R2. Hybridomas positive for $\mathrm{mR} 2$ were selected using anti-rat $\mathrm{IgG}$ HRP (Jackson Immunochemicals) as detection and TMB (Pierce Biochemicals) as substrate. Positive hybridomas were further selected for the absence of anti-Fc reactivity by repeating the ELISAs using $\mathrm{mIgG} 2 \mathrm{a}$ as the capture antigen. Table 2 summarizes the properties of five anti$\mathrm{mR} 2$ monoclonal antibodies judged by ELISA, FACS and westerns. 
Table 1. Predicted molecular weight of mCD200 receptors and mCD200R-Fc fusion proteins (+/- N glycan chains) ${ }^{\mathrm{a}}$.

\begin{tabular}{cccccc}
\hline $\begin{array}{c}\text { Receptor } \\
\text { protein }\end{array}$ & Amino acids & N-glycans & $\begin{array}{c}\text { Estimated Mr from protein } \\
\text { composition }\end{array}$ & $\begin{array}{c}\text { Measured Mr } \\
\text { (PAGE) }\end{array}$ & $\begin{array}{c}\text { Estimated Mr glycans (measured } \\
\text { Mr-Mr Protein) }\end{array}$ \\
\hline $\mathrm{mR} 1$ & 326 & 10 & $35.8 \mathrm{kDa}$ & $90 \mathrm{kDa}$ & $54.2 \mathrm{kDa}$ \\
$\mathrm{mR} 2$ & 249 & 6 & $27.4 \mathrm{kDa}$ & $60 \mathrm{kDa}$ & $32.6 \mathrm{kDa}$ \\
$\mathrm{mR} 4$ & 270 & 9 & $29.7 \mathrm{kDa}$ & $50 \mathrm{kDa}$ & $20.3 \mathrm{kDa}$ \\
$\mathrm{mR} 1 \mathrm{Fc}$ & 447 & 11 & $49.1 \mathrm{kDa}$ & $98 \mathrm{kDa}$ & $48.9 \mathrm{kDa}$ \\
$\mathrm{mR} 2 \mathrm{Fc}$ & 426 & 7 & $46.8 \mathrm{kDa}$ & $70 \mathrm{kDa}$ & $23.2 \mathrm{kDa}$ \\
$\mathrm{mR} 4 \mathrm{Fc}$ & 447 & 10 & $49.1 \mathrm{kDa}$ & $95 \mathrm{kDa}$ & $49.1 \mathrm{kDa}$ \\
\hline
\end{tabular}

${ }^{\mathrm{a}}$ Full length mouse CD200 receptors are designated $\mathrm{mR} 1, \mathrm{mR} 2$ and $\mathrm{mR} 4 . \mathrm{mIgG} 2 \mathrm{a}$ fusion proteins of the same receptors are designated $\mathrm{mR} 1 \mathrm{Fc}, \mathrm{mR} 2 \mathrm{Fc}$ and mR4Fc.

Table 2. Characterization of anti-R2 Monoclonals.

\begin{tabular}{|c|c|c|c|c|c|c|c|c|}
\hline \multicolumn{4}{|c|}{$\mathrm{FACS}^{\mathrm{a}}$} & \multicolumn{4}{|c|}{ ELISA $^{\mathrm{b}}$} & \multirow{2}{*}{$\begin{array}{c}\text { Western }^{\mathrm{c}} \\
\text { R2V5 }\end{array}$} \\
\hline & (R2V5) & (R1his) & (R4V5) & $\mathrm{R} 2 \mathrm{Fc}$ & $\mathrm{R} 1 \mathrm{Fc}$ & $\mathrm{R} 4 \mathrm{Fc}$ & $\mathrm{CD} 200 \mathrm{Fc}$ & \\
\hline $4 \mathrm{H} 4$ & + & - & - & + & - & - & - & - \\
\hline $6 \mathrm{E} 4$ & + & - & - & + & - & - & - & - \\
\hline $9 \mathrm{~B} 6$ & + & - & - & + & - & - & - & + \\
\hline $5 \mathrm{~A} 4$ & - & - & - & + & - & - & - & + \\
\hline 1D2 & - & + & - & + & + & - & + & - \\
\hline
\end{tabular}

${ }^{\mathrm{a}} 1 \mathrm{H} 8,4 \mathrm{H} 4,6 \mathrm{E} 4,9 \mathrm{~B} 6,5 \mathrm{~A} 4$ represent anti-R2 specific mAbs. 1D2 represents an anti-R2 mAb recognizing cell surface mR1. Hek293 cells were transiently transfected with R2V5, R1his, or R4V5 and immunostained with anti-mR2 mAbs. A clone was stated as positive with $\geq 90 \%$ staining of transfected cells; ${ }^{\mathrm{b}} \mathrm{R} 2 \mathrm{Fc}$, $\mathrm{R} 1 \mathrm{Fc}, \mathrm{R} 4 \mathrm{Fc}$ and CD200Fc represent Fc fusion proteins of receptors R2, R1, R4 and CD200 used in ELISA to determine the specificity of anti-mR2 mAbs; ${ }^{\circ} \mathrm{Cell}$ lysates from R2V5 transfected cells were subjected to SDS/PAGE and western blotting using anti-R2 mAbs.

\subsection{Cloning and Expression of C-Terminally Tagged Full Length mCD200 Receptors in Hek293}

Full length mCD200Rs derived from previously described full length cDNA clones were subcloned into the pIRESneo3 vector with addition of different epitope tags at the carboxy terminus [1]. mR1 was tagged with (his) 6 and $\mathrm{mR} 2$ and $\mathrm{mR} 4$ both carried the V5 epitope tag. Mouse Dap12 protein was subcloned into the pIRESneo3 vector from an I.M.A.G.E. clone (6814478) containing the full length cDNA sequence.

Each tagged receptor (namely mR1his, mR2V5 and mR4V5) was transiently expressed in Hek293 cells and $24 \mathrm{~h}$ post transfection cell lysates were subjected to SDS/ PAGE and western blotting using anti-his or anti-V5 antibodies.

For immunoprecipitation studies cells were lysed in RIPA buffer containing protease inhibitor cocktail. Specific antibody and Protein A/G Agarose beads (Pierce Biochemicals) were added to clear the supernatant and the mixture incubated overnight with shaking at $4^{\circ} \mathrm{C}$. The
antigen-antibody-Protein $\mathrm{A} / \mathrm{G}$ complex was washed twice with RIPA, boiled in reduced sample buffer and subjected to SDS/PAGE and western blotting using the appropriate antibody.

Stable cell lines of Hek293 expressing mR2V5 were established following cloning and screening by western blot using anti-V5 antibody.

\subsection{Carboxy Terminal Domain Switching between CD200 Receptors}

The transmembrane (TM) and cytoplasmic (CT) region of $\mathrm{mR} 1, \mathrm{mR} 2$ and $\mathrm{mR} 4$ were generated by PCR using the full length CD200 receptors described above as template. Following BamHI and AgeI digestion, the fragments were ligated into a BamHI/AgeI digested pIRESneo3 expression vector encoding the extracellular region of the CD200 receptors. The receptor chimeras generated were given the nomenclature $\mathrm{mR}_{\mathrm{x}} \mathrm{r}_{\mathrm{y}}$ where " $\mathrm{x}$ " represents the source of the extracellular domain and " $y$ " the transmembrane and cytoplasmic domain. $\mathrm{mR}_{1} \mathrm{r}_{2}, \mathrm{mR}_{1} \mathrm{r}_{4}, \mathrm{mR}_{2} \mathrm{r}_{1}$, $\mathrm{mR}_{2} \mathrm{r}_{4}$, and $\mathrm{mR}_{4} \mathrm{r}_{1}$ were transfected into Hek293/CHOK 
cells in serum free medium using lipofectamine. $24 \mathrm{~h}$ post transfection cell lysates were subjected to SDS/ PAGE and western blotting using appropriate antibody.

In some studies, tunicamycin at $50-100 \mathrm{ng} / \mathrm{ml}$ was added $5 \mathrm{~h}$ post transfection and maintained during the entire time of experiment to block N-linked glycosylation.

\subsection{Binding and Activation of CD200 Receptor R1/R2 and Receptor Chimeras with $\mathrm{mCD} 200 \mathrm{Fc} / \mathrm{Shed}$ Soluble mCD200}

Cells were transfected using lipofectamine 2000 with receptor chimeras as described. $24 \mathrm{~h}$ post transfection, cells were washed with cold PBS, and incubated with purified dimeric $\mathrm{mCD} 200 \mathrm{Fc}(5 \mu \mathrm{g} / \mathrm{ml})$ for $15 \mathrm{~min}$ at $37^{\circ} \mathrm{C}$, followed by staining with FITC/PE labeled anti-mouse $\mathrm{IgG}(\mathrm{Fab})_{2}$. Binding of mCD200Fc was assessed by flow cytometry. Mouse Fc fragment (purchased from Pierce Biochemicals) was used as a negative control.

For activation studies, supernatants from $48 \mathrm{~h}$ serum starved mCD200-expressing Hek293 cells (containing shed soluble CD200), confirmed by ELISA and westerns using antibody to CD200 [20] were incubated for $15 \mathrm{~min}$ at $37^{\circ} \mathrm{C}$ with cells expressing different CD200Rs or CD200 receptor chimeras with or without mouse Dap12. Cells were lysed in RIPA buffer containing $50 \mathrm{mM} \mathrm{NaF}$, $1 \mathrm{mM} \mathrm{Na} \mathrm{VO}_{4}$, and protease inhibitors. Cleared lysates were immunoprecipitated overnight at $4^{\circ} \mathrm{C}$ with one of the following antibodies: 2A10; commercial anti-phosphotyrosine antibody (Millipore); rabbit polyclonal antibody to the tyrosine phosphorylated cytoplasmic region of mR1 (a gift from Dr. Karim Berrada, Ingenious Therapetics, NY, USA); or polyclonal antibody to mouse Dap12 (Alpha Diagnostics).

The immune complexes were recovered by incubation with ProteinA/G Agarose beads (Pierce Biochemicals) for $1 \mathrm{~h}$ at $4^{\circ} \mathrm{C}$. After washing twice in lysis buffer containing $1 \mathrm{mM} \mathrm{Na}_{3} \mathrm{VO}_{4}$, the immune complexes were dissociated by boiling in reduced SDS/PAGE sample buffer followed by SDS/PAGE and western blotting. Primary Abs were detected with HRP-conjugated secondary Abs (Jackson Immunochemicals) and chemiluminescence substrate.

\section{RESULTS}

\subsection{Characterization of Anti-mR2 Monoclonals}

A total of 17 anti-mR2 monoclonals were generated and characterized for their specificity. Table 2, summarizes the characteristics of five monoclonals specific for mR2 as judged by ELISA, flow cytometry and westerns. FACS data for Hek293 cells stably transfected with $\mathrm{mR} 2 \mathrm{~V} 5$ and immunostained with the different anti-mR2 monoclonals are shown in Figure 1(A). Anti-mR2 monoclonals namely 9B6/6E4, 1H8, and 4H4 recognized mR2 expressed on the cell surface with no immunoreactivity towards cells expressing mR1 or mR4V5 (Supplementary Figure 1). Hek293 cells transiently transfected with mR2 (lacking a C-terminal tag) gave essentially similar results with the four anti-mR2 specific antibodies (not shown). As judged by westerns, mR2 and mR2V5 protein was best detected in transfected cell lysates using the two anti-mR2 monoclonals 5A4 and 9B6 (Figure 1(B)). As noted, while 9B6 was able to detect both cell surface $\mathrm{mR} 2$ in FACS and $\mathrm{mR} 2$ in western gels (at molecular mass $60 \mathrm{kDa}$ ), monoclonal 5A4 could only recognize $\mathrm{mR} 2$ protein by westerns (see Table 2 ).

\subsection{Characterization of Anti-mR1 Monoclonals}

As shown in Figure 2(A), anti-mR1 2A10, the mAb secreted following immunization with $\mathrm{mR} 1$ his was able to detect $\mathrm{mR} 1$ expressed on the cell surface of Hek293 cells and was superior in this regard to the commercial anti-mR1 antibody (AbD Serotec, MorphoSys). 2A10, unlike the commercial anti-mR1, was also able to detect $\mathrm{mR} 1$ protein by western blots whereas cell lysates of mR2V5 and mR4V5 transfected cells showed no immunoreactivity (Figure 2(B)). However, neither 2A10 nor the commercial anti-mR1 antibody was specific for cell surface $\mathrm{mR} 1$, since flow cytometric analyses showed that both antibodies also stained cells expressing mR2V5 (Supplementary Figures 2(A) and (B)) with insignificant immunoreactivity with mR4V5 transfected cells (Supplementary Figures 2(C) and (D)). We conclude that though anti-R2 specific monoclonals show specificity in western blots and FACS, unique anti-R1 specific monoclonals, as analyzed by FACS staining, have yet to be described.

\subsection{Cloning and Expression of $m C D 200$ Receptor-Fc Fusion Proteins in CHOK Cells}

Fc fusion proteins for the four mouse CD200Rs were generated by linking the extracellular region of each receptor to the Fc region of $\mathrm{mIgG} 2 \mathrm{a}$ in the expression vector pIRESneo3. The number of N-glycans and the predicted molecular weight of the full length receptors and their Fc fusion proteins are shown in Table 1. Receptor fusion proteins (mR1Fc-mR4Fc) were transiently expressed in $\mathrm{CHOK}$ and supernatants analyzed by SDS/PAGE and westerns using an anti-IgG2a antibody. As shown in Figure 3(A), the molecular weight of each receptor fusion protein was related to the number of $\mathrm{N}$-glycans, with mR1Fc detected at molecular mass 98 $\mathrm{kDa}, \mathrm{mR} 4 \mathrm{Fc}$ at $95 \mathrm{kDa}, \mathrm{mR} 2 \mathrm{Fc}$ at $70 \mathrm{kDa}$ and $\mathrm{mR} 3 \mathrm{Fc}$ at 

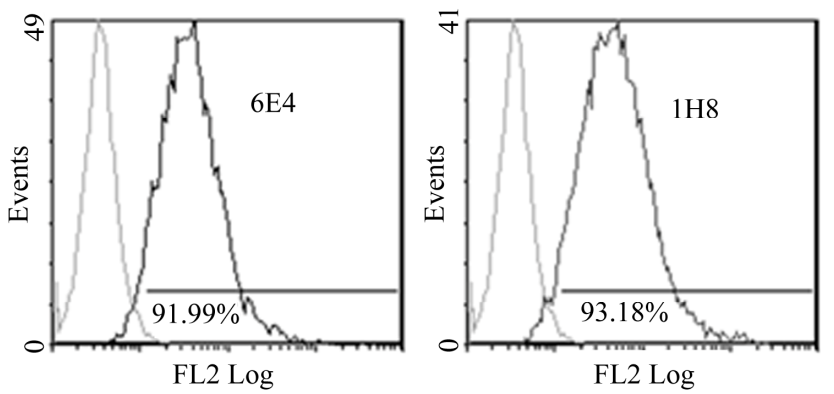

Expression of full length $\mathrm{mR} 2 \mathrm{~V} 5$ and

mR2 in Hek293 cells

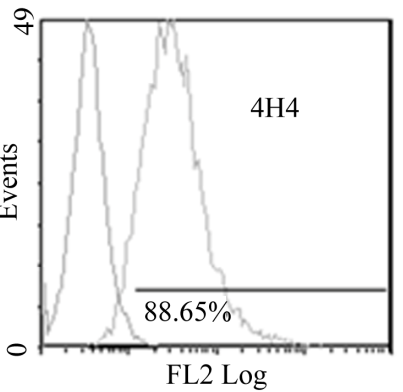

(A)

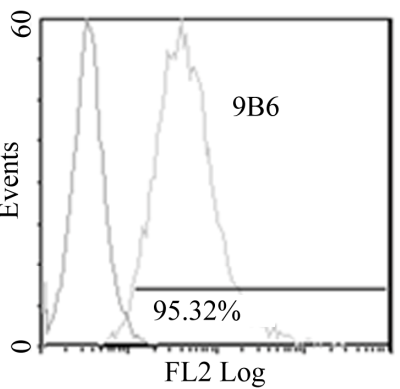

FL2 Log

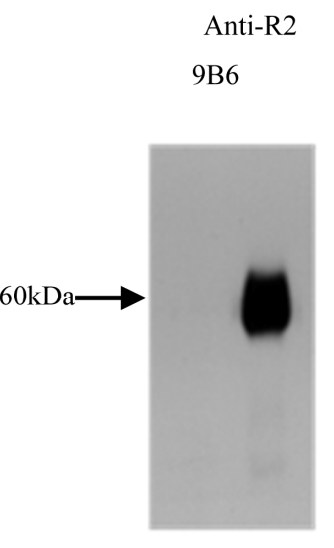

12 antibody

$5 \mathrm{~A} 4$

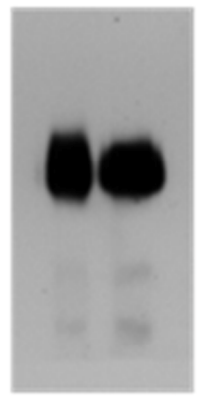

34

(B)

Figure 1. Characterization of anti-mR2 monoclonals. (A) Flow cytometry data for Hek293 cells stably transfected with mR2V5 were immunostained with anti-mR2 monoclonals 6E4, 1H8, 4H4 and 9B6; (B) Lysates (25 $\mu$ g protein) of Hek293 cells transfected with mR2V5 (lanes 2 and 3), and mR2 (lane 4) were subjected to SDS/PAGE and western blotting using anti-R2 antibody 9B6 and 5A4. Lane 1 represents lysates of mock transfected cells.

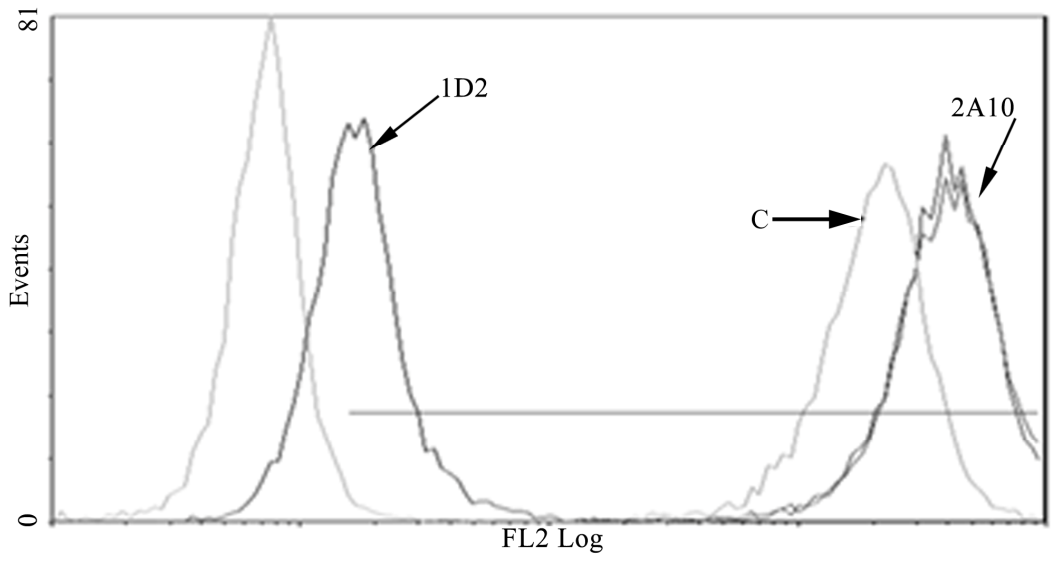

(A)

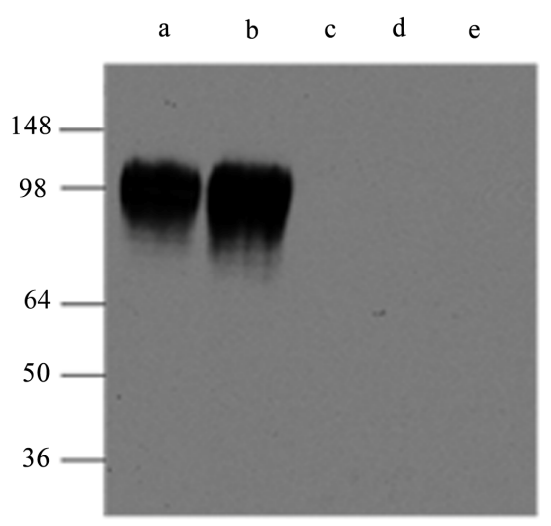

(B)

Figure 2. Characterization of anti-mR1 monoclonals. (A) Flow cytometry data of Hek293 cells stably transfected with mR1 and immunostained with $\mathrm{mR} 1$ monoclonal $2 \mathrm{~A} 10(0.1$ and $0.5 \mathrm{~g})$. C represents staining with $(0.5 \mathrm{~g})$ commercial anti-mR1 and 1D2 represents staining by a monoclonal antibody $(0.5 \mu \mathrm{g})$ raised by injection of $\mathrm{mR} 2 \mathrm{Fc}$ with so significant binding to mR2 by FACS and western; (B) Lysates (25 $\mu \mathrm{g}$ protein) of cells transfected with mR1 (a, b), with mR2V5 (c) with mR4V5 (d) and mock transfected Hek293 cells (e) were subjected to SDS/PAGE and western using anti-R1 monoclonal 2A10. Molecular weight markers are indicated.

Mr 65 kDa.

\subsection{Characterization of Full Length CD200 Receptors mR1his, mR2V5 and mR4V5 Expressed in Hek293 Cells}

Full length CD200 receptors with C-terminal tags namely mR1his, mR2V5 and mR4V5 were expressed in Hek293 cells. $24 \mathrm{~h}$ post transfection, cells were lysed in the presence of protease inhibitors and lysates subjected to SDS/PAGE and westerns usinSg anti-his or anti-V5 antibody. As shown in Figure 3(B), mR1his was detected at molecular mass $90 \mathrm{kDa}$ and mR2V5 at $60 \mathrm{kDa}$, the sizes expected for glycosylated receptors (Figure 3(B), 
panels a and b). However, in mR4V5 transfected cells, despite the presence of protease inhibitors during cell lysis, the prominent band for mR4V5 appears to be at molecular mass of $26 \mathrm{kDa}$ (Figure 3(B), panel c).

Cell lysates of mR4V5 transfected cells fractionated into membrane and cytosolic fractions are shown in Figure 3(C). The molecular mass of mR4V5 in the membrane fraction was $48 \mathrm{kDa}$ (Figure 3(C), lane 7) whereas the cytosolic fraction showed a $26 \mathrm{kDa}$ product similar to that seen in cell lysates (Figure 3(B), lane 8). Thus, even though $\mathrm{mR} 4$ and $\mathrm{mR} 1$ share high homology in their extracellular region and contain similar numbers of potential N-glycan sites, mR4V5 appears to be far less glycosylated. Replacing the TM and cytoplasmic region of $\mathrm{mR} 4$ with an Fc fragment restored the molecular mass of $\mathrm{mR} 4 \mathrm{Fc}$ to the size expected from the number of N-glycans (i.e. $95 \mathrm{kDa}$, Figure 3(A)), suggesting that the carboxy terminal region of the CD200Rs can regulate the difference in the degree of glycosylation in $\mathrm{mR} 1 \mathrm{vs} \mathrm{mR} 4$.

\subsection{N-linked Glycan Differences between mR2V5 and mR4V5}

To investigate differences in the degree of glycosylation in mR2V5 and mR4V5, Hek293 cells were transfected with mR2V5 or mR4V5 in the presence/absence of tunicamycin and cell lysates harvested $24 \mathrm{~h}$ post transfection. As shown in Figure 4, the presence of tunicamycin produced a significant drop in the molecular mass of mR2 25 from $60 \mathrm{kDa}$ to $29 \mathrm{kDa}$, the expected molecular mass of the non-glycosylated mR2. Expression of mR4V5 in the presence of tunicamycin produced no change in the molecular weight of the cell lysate product detected by anti-V5 antibody. We conclude that the 26 $\mathrm{kDa}$ mR4V5 likely represents a non-glycosylated molecule.

In membrane fractions of transfected cells, mR4V5 is present at a molecular mass of $48 \mathrm{kDa}$ (Figure 3(C), lane 7) and in the presence of tunicamycin, the molecular mass dropped to $26 \mathrm{kDa}$ (Figure 3(C), lane 9). The 26 $\mathrm{kDa}$ product observed in the cytosolic fraction that remained unchanged following treatment with tunicamycin (Figure 3(C), lanes 8 and 10) likely represents the cytoplasmic non-glycosylated form of mR4V5.

Expression of $\mathrm{mR} 1 \mathrm{his}$ in the presence of tunicamycin produced two bands at $52 \mathrm{kDa}$ and $34 \mathrm{kDa}$ (Figure 4(C)), which may reflect the presence of both $\mathrm{N}$ and O-linked glycan chains. Given that $\mathrm{mR} 1$ and $\mathrm{mR} 4$ share over $85 \%$ amino acid identity in their extracellular $\mathrm{V}+\mathrm{C}$ region, with all $\mathrm{N}$-glycan sites conserved, the differences in the observed molecular mass (90 $\mathrm{kDa}$ vs $48 \mathrm{kDa}$ ) suggests that the carboxy terminal region of CD200Rs regulates the differences in the degree of glycosylation in $\mathrm{mR} 1 \mathrm{vs}$ mR4.

\subsection{Lack of Heterodimerization after Co-Expression of $\mathrm{mR} 1$ and $\mathrm{mR2}$ in Hek293 Cells}

Hek293 cells stably expressing mR1 were transiently transfected with mR2V5 and $24 \mathrm{~h}$ post transfection, the surface expression of $\mathrm{mR} 2 \mathrm{~V} 5$ in cells expressing $\mathrm{mR} 1$ was confirmed using anti-mR2 specific antibody $4 \mathrm{H} 4$ (Supplementary Figure 3(A)). RIPA cell lysates of the transfected cells were analyzed by western blotting with anti-V5 antibody and anti-mR1 (2A10) as shown in (Supplementary Figure 3(B)), to confirm co-expression of the molecules. When dual transfected cells were immunoprecipitated with anti-V5 and analyzed on westerns using $2 \mathrm{~A} 10$ and 5A4, only the latter mAb (Supplementary Figure 3(C), lane 1) gave a protein band, with no bands detected by 2A10 (Supplementary Figure 3(D), lane 3). These data suggest that despite co-expression on the same cell, receptors $\mathrm{mR} 1$ and $\mathrm{mR} 2$ do not heterodimerize. When cells were immunoprecipitated with $2 \mathrm{~A} 10$, with the immunoprecipitates analyzed by western blotting using anti-V5 antibody, this conclusion was confirmed with no band detected on westerns by $5 \mathrm{~A} 4$ (data not shown).

\subsection{Effect of Carboxy Terminal Domain Switching between CD200 Receptors}

Using molecular cloning techniques, the TM and cytoplasmic region of $\mathrm{mR} 1$ was replaced with the corresponding regions of $\mathrm{mR} 2$. The newly generated chimeric receptor $\mathrm{mR}_{1} \mathrm{r}_{2}$ when expressed in Hek293, resulted in a protein with molecular mass of $45 \mathrm{kDa}$, unlike $\mathrm{mR} 1$ with observed molecular mass $90 \mathrm{kDa}$ (Figure 5(A)). In the presence of tunicamycin, the molecular mass of $\mathrm{mR}_{1} \mathrm{r}_{2}$ was further reduced to $30 \mathrm{kDa}$, the size expected for $\mathrm{mR}_{1} \mathrm{r}_{2}$ protein (Figure 5(B)). Replacing the TM and cytoplasmic region of $\mathrm{mR} 1$ with the corresponding region of mR4 gave essentially the same results. The newly generated chimeric receptor $\mathrm{mR}_{1} \mathrm{r}_{4}$ when expressed in Hek293 appeared at the same molecular mass as $\mathrm{mR}_{1} \mathrm{r}_{2}$ (i.e. $45 \mathrm{kDa}$ ). When expressed in the presence of tunicamycin the molecular mass of $\mathrm{mR}_{1} \mathrm{r}_{4}$ was reduced to $30 \mathrm{kDa}$, the size expected for $\mathrm{mR}_{1} \mathrm{r}_{4}$ protein (Figure 5(C)). Thus the TM and cytoplasmic region of $\mathrm{mR} 1$ when replaced with the corresponding regions of either $\mathrm{mR} 2$ or $\mathrm{mR} 4$, reduced the glycosylation of $\mathrm{mR} 1$ by $\sim 50 \%$. Lower molecular weight bands in Figure 5(A) likely represent non-specific bands.

Replacing the TM and cytoplasmic region of $\mathrm{mR} 2$ with the corresponding region of $\mathrm{mR} 1$ did not produce a significant drop in the molecular mass of the chimeric receptor $\mathrm{mR}_{2} \mathrm{r}_{1}$ (Figure 6(A)). We interpret this as indicating that the TM and cytoplasmic region of $\mathrm{mR} 1 \mathrm{did}$ not influence the glycosylation state of $\mathrm{mR} 2$, even 


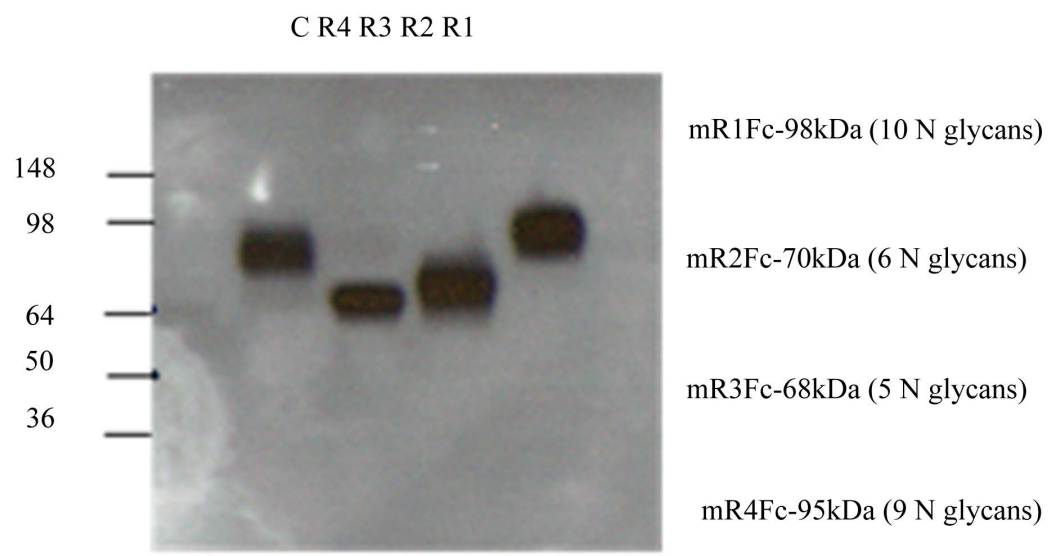

(A)

(a)

R 1his

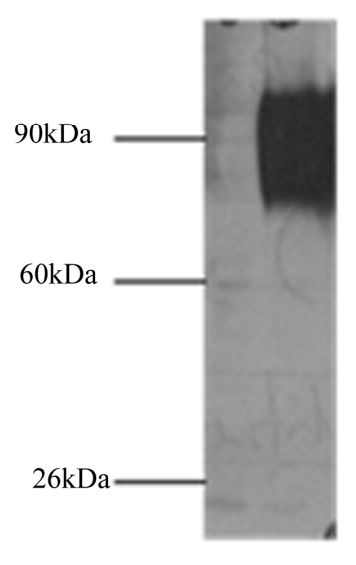

12 (b)
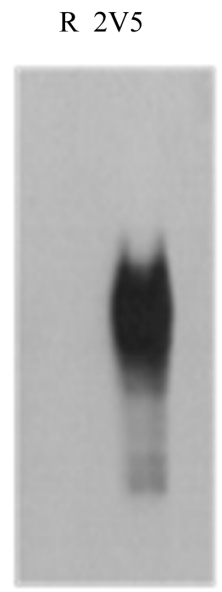

34

(B) (c)

R 4V5

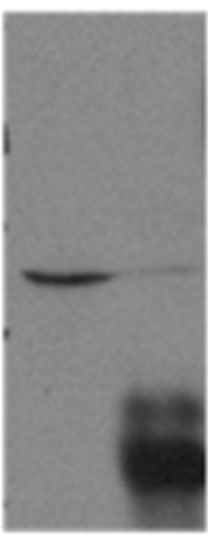

6

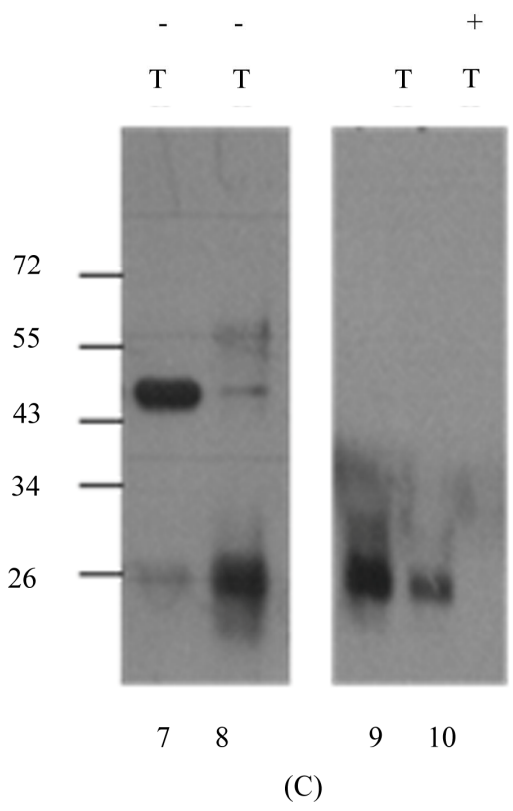

Figure 3. Characterization of $m C D 200 R-F c$ fusion/full length mCD200 receptor. proteins (A) Supernatants from Hek293 cells transfected with CD200R-Fc fusion proteins namely mR1Fc (R1), mR2Fc (R2), mR3Fc (R3) and mR4Fc (R4) were subjected to SDS/PAGE and western blotting using anti-mouse IgG2a antibody. (C) represents mock transfected cells. Molecular weight markers are indicated; (B) Lysates (25 $\mu \mathrm{g}$ protein) of Hek293 cells transfected with mR1his (panel a, lane 2), mR2V5 (panel b,lane 4) or mR4V5 (panel c, lane 6) subjected to SDS/PAGE and western blotting using anti-his antibody (a) or anti-V5 antibody (b \& c). Lanes 1, 3 and 5 represent lysates of mock transfected cells; (C) Hek293 cells transfected with mR4V5 (lanes 7 - 10) and separated into membrane (lanes 7,9) and cytosolic (lanes 8,10) fractions were subjected to SDS/PAGE and western blotting using anti-V5 antibody. $-/+\mathrm{T}$ represents transfections in the absence and presence of tunicamycin. Molecular weights markers are indicated.

though the corresponding region of $\mathrm{mR} 2$ did reduce the glycosylation of $\mathrm{mR} 1$ by about $50 \%$. In contrast, replacing the TM and cytoplasmic region of $\mathrm{mR} 2$ with the corresponding regions of $\mathrm{mR} 4$, resulted in a significant drop in the molecular mass of the chimeric receptor $\mathrm{mR}_{2} \mathrm{r}_{4}$ (Figure 6(B)). Compared to $\mathrm{mR} 2$ with $\sim$ molecular mass $60 \mathrm{kDa}$, the chimeric receptor $\mathrm{mR}_{2} \mathrm{r}_{4}$ was detected at 40 $\mathrm{kDa}$ as judged by western blots using 5A4 antibody. Expressing $\mathrm{mR}_{2} \mathrm{r}_{4}$ in the presence of tunicamycin resulted in an unexpected loss of the epitope detected by $5 \mathrm{~A} 4$ on westerns (Figure 6(B)) although this was not seen with
mR2V5 transfected cells grown in the presence of tunicamycin (see Figure 4(A)).

Similar to $\mathrm{mR}_{1} \mathrm{r}_{1}(=\mathrm{mR} 1)$ and $\mathrm{mR}_{2} \mathrm{r}_{2}(=\mathrm{mR} 2)$, chimeric receptors $m R_{1} r_{2}, m_{1} r_{4}, m R_{2} r_{1}$ were expressed at the cell surface as judged by flow cytometry analyses using antibody 2A10 (Supplementary Figure 4(A)) and also bound mCD200Fc (Supplementary Figure 4(B)). Since the chimeric receptors are transiently expressed, their binding to $\mathrm{mCD} 200 \mathrm{Fc}$ could only be assessed qualitatively.

Despite the fact that $\mathrm{mR}_{2} \mathrm{r}_{1}$ transfected cells main 


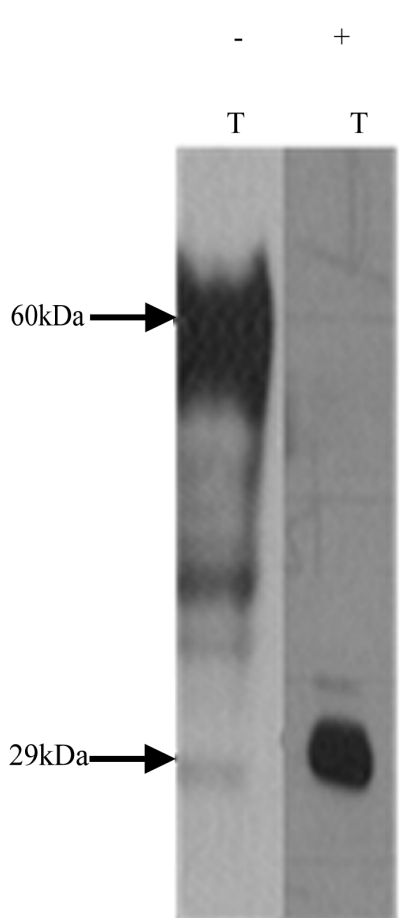

(A)

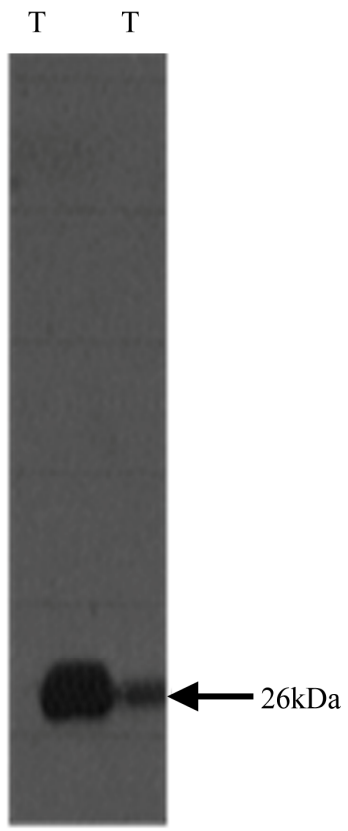

(B)

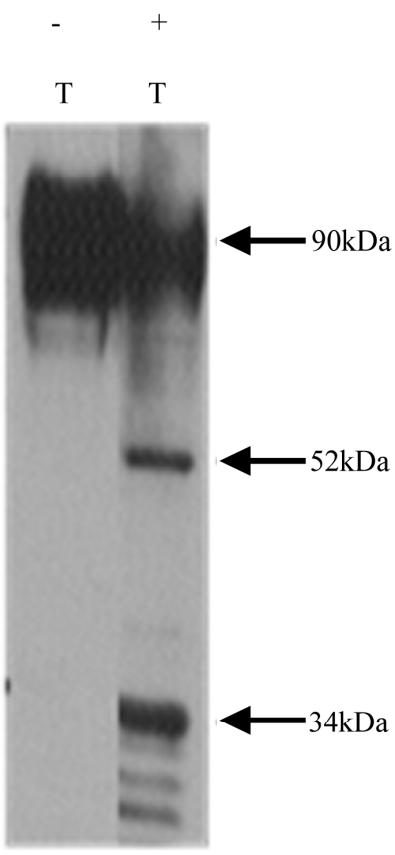

(C)

Figure 4. N-linked glycan differences between mR2V5 and mR4V5. Hek293 cells transfected with mR2V5 (A), mR4V5 (B) and $\mathrm{mR} 1$ his $(\mathrm{C})$ were incubated with medium containing $100 \mathrm{ng} / \mathrm{ml}$ tunicamycin for $24 \mathrm{~h}$ at $37^{\circ} \mathrm{C}$. Protease inhibitor containing cell lysates were subjected to SDS/PAGE and westerns using anti-V5 antibody (a and b) and antibody $2 \mathrm{~A} 10$ (C). $-/+$ T represent absence or presence of tunicamycin in the medium.

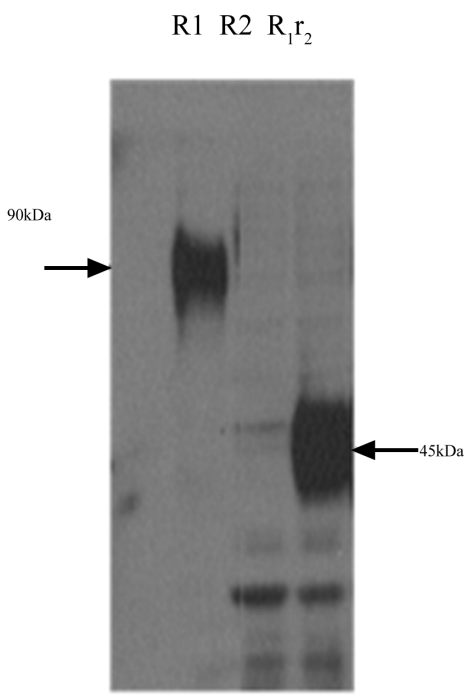

(A)

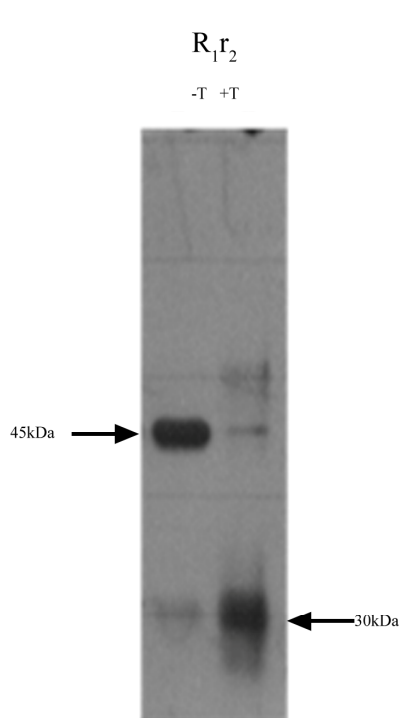

(B)

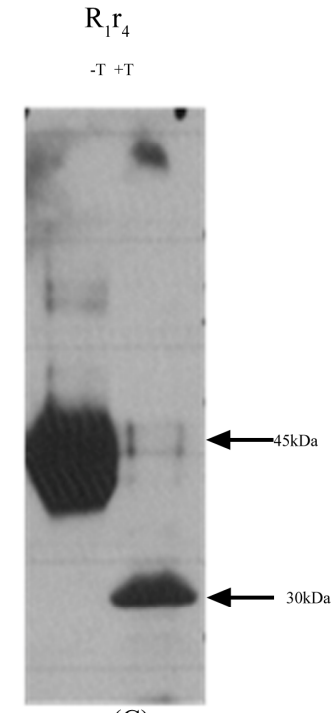

(C)

Figure 5. Effect of carboxy terminal domain switching between CD200 receptors $m R_{1} r_{2}$ and $m R_{1} r_{4}$. (A) Chimeric receptor mR $r_{2}$ was transiently expressed in Hek293 cells, $24 \mathrm{~h}$ post transfection cell lysates were subjected to SDS/PAGE and western blotting using anti-R1 antibody 2A10; Cell lysates of Hek293 cells transiently transfected with mR1 (lacking a his C-terminal tag), served as positive control, and lysates of $\mathrm{mR} 2$ (lacking a V5 C-terminal tag) served as negative control; (B) Chimeric receptor $\mathrm{mR}_{1} \mathrm{r}_{2}$ expressed in the presence $(+\mathrm{T})$ or absence $(-\mathrm{T})$ of tunicamycin with lysates subjected to SDS/PAGE and western blotting using anti-R1 antibody 2A10; (C) Chimeric receptor $\mathrm{mR}_{1} \mathrm{r}_{4}$ expressed in the presence $(+\mathrm{T})$ or absence $(-\mathrm{T})$ of tunicamycin with lysates subjected to SDS/PAGE and western blotting using anti-R1 antibody 2A10. Cell lysates for western blotting were used at concentration of $25-30$ $\mu \mathrm{g}$ protein. 


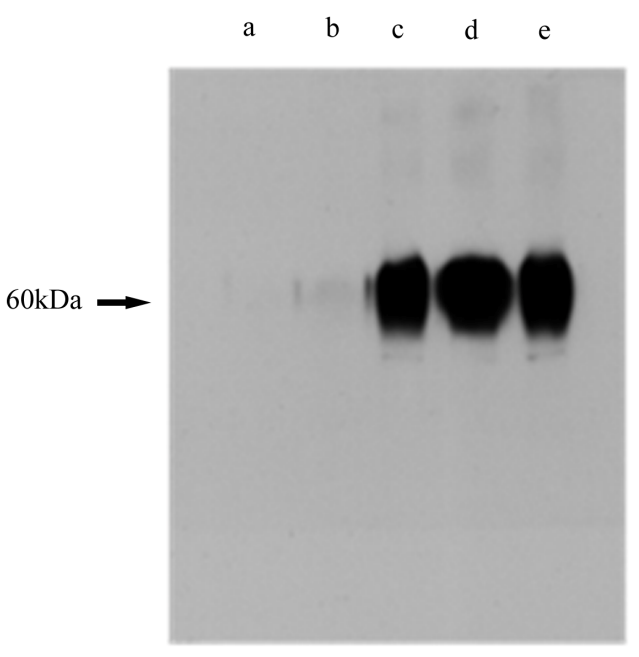

(A)

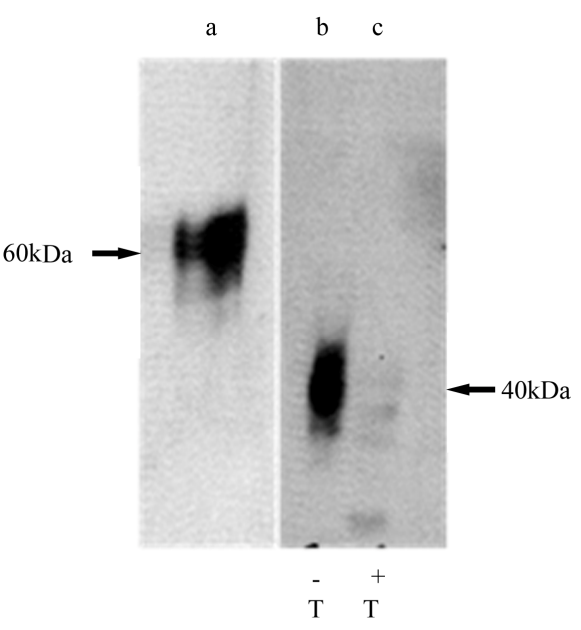

(B)

Figure 6. Effect of carboxy terminal domain switching between CD200 receptors $\mathrm{mR}_{2} \mathrm{r}_{1}$ and $\mathrm{mR}_{2} \mathrm{r}_{4}$. (A) Chimeric receptor $m R_{2} \mathrm{r}_{1}$ was transiently expressed in Hek293 cells (lane c). $24 \mathrm{~h}$ post transfection cell lysates were subjected to SDS/PAGE and western blotting using anti-R2 antibody 5A4. Cell lysates of Hek293 cells transiently transfected with mR2 (lacking C-terminal tag) (lane d) and mR2V5 (lane e) served as appropriate control. Mock transfected cells and mR1 transfected cells are shown in lanes a and b respectively; (B) Chimeric receptor $\mathrm{mR}_{2} \mathrm{r}_{4}$ was transiently expressed in Hek293 cells, and $24 \mathrm{~h}$ post transfection cell lysates were subjected to SDS/PAGE and western blotting with anti-R2 antibody 5A4. Lanes b and c represent mR2r4 transfected cells in the presence $(+\mathrm{T})$ and absence $(-\mathrm{T})$ of tunicamycin. Lane a represents lysates of $\mathrm{mR} 2$ transfected cells. Cell lysates for western blotting were used at concentration of $25-30 \mu \mathrm{g}$ protein.

tained their immunoreactivity with the R2 specific monoclonals (Supplementary Figure 4(C) panel a), cells transfected with chimeric receptor $\mathrm{mR}_{2} \mathrm{r}_{4}$ could not be detected by flow cytometry using R2 specific antibodies (Supplementary Figure $\mathbf{4}(\mathrm{C})$ panel b). Furthermore, $\mathrm{mR}_{2} \mathrm{r}_{4}$ transfected cells failed to bind $\mathrm{mCD} 200 \mathrm{Fc}$ (data not shown). Expression of R4 (tagged with V5 i.e. R4V5) could only be detected by westerns using anti-V5 antibody in cell lysates of mR4V5 transfected cells (Figure 3(C)). In the absence of anti-mR4 specific antibodies, we have been unable to characterize any cell surface expression of $\mathrm{mR} 4$ and appraise its binding to $\mathrm{mCD} 200$.

\subsection{Functional Activation of Chimeric Receptors R2r1, R1r2 and R1r4 after Stimulation by $\mathrm{mCD} 200$}

Hek293 cells transfected with $\mathrm{R}_{2} \mathrm{r}_{1}$ or R1 were stimulated at $37^{\circ} \mathrm{C}$ for $15 \mathrm{~min}$ with soluble CD200 released into the supernatant of serum starved mCD200 expressing cells [20]. Cell lysates prepared in RIPA buffer containing protease as well as phosphatase inhibitors were immunoprecipitated using antibody against the phosphorylated cytoplasmic tail of $\mathrm{mR} 1$ or the commercial anti-phosphotyrosine antibody followed by western using antibody 2A10 (Figure 7). Similar to data observed with $\mathrm{mR} 1$, stimulation of $\mathrm{mR}_{2} \mathrm{r}_{1}$ with $\mathrm{mCD} 200$ resulted in tyrosine phosphorylation of the cytoplasmic domain $\left(\mathrm{r}_{1}\right)$ of this chimeric receptor. Thus replacing the TM and CT region of $\mathrm{R} 2$ with that of $\mathrm{R} 1$ results in a receptor $\left(\mathrm{R}_{2} \mathrm{r}_{1}\right)$ that binds CD200 and functionally mimics CD200R1 (with phosphorylation of the cytoplasmic tail) following CD200 binding.

Hek293 cells were also co-transfected with mDap12 and $\mathrm{mR} 2 \mathrm{~V} 5, \mathrm{mR} 4 \mathrm{~V} 5, \mathrm{mR}_{1} \mathrm{r}_{2}$ or $\mathrm{mR}_{1} \mathrm{r}_{4}$ and stimulated with soluble $\mathrm{mCD} 200$, with immunoprecipitates analyzed by westerns. Lysates of cells transfected with mR2V5 and mR4V5 were immunoprecipitated with anti-V5 antibody whereas lysates from $\mathrm{mR}_{1} \mathrm{r}_{2}$ and $\mathrm{mR}_{1} \mathrm{r}_{4}$ transfected cells were immunoprecipitated with anti-phosphotyrosine antibody. All immunoprecipitates were analyzed by westerns using anti-dap12 antibody. As shown in Figure 8(A) (panel e), lysates from $\left(\mathrm{mR}_{1} \mathrm{r}_{2}+\right.$ Dap12) and $\left(\mathrm{mR}_{1} \mathrm{r}_{4}+\right.$ Dap12) transfected cells analyzed by westerns using antibody $2 \mathrm{~A} 10$ showed the expected product size of $45 \mathrm{kDa}$ for $\mathrm{mR}_{1} \mathrm{r}_{2}$ and $\mathrm{mR}_{1} \mathrm{r}_{4}$.

All 4 receptors namely $\mathrm{mR} 4 \mathrm{~V} 5, \mathrm{mR} 2 \mathrm{~V} 5, \mathrm{mR}_{1} \mathrm{r}_{2}$ and $\mathrm{mR}_{1} \mathrm{r}_{4}$ associated with Dap12 when cotransfected. However, Dap12 phosphorylation occured only after stimulation and mCD200 binding to either mR2V5 (Figure 8(A), panel b) or the chimeric receptors $\mathrm{mR}_{1} \mathrm{r}_{2}$ and $\mathrm{mR}_{1} \mathrm{r}_{4}$ (Figure 8(A), panels c and d). No Dap12 phosphorylation was seen in mR4V5 transfected cells following stimulation (Figure 8(A)). Thus having switched the carboxy terminal region, both $\mathrm{mR}_{1} \mathrm{r}_{2}$ and $\mathrm{mR}_{1} \mathrm{r}_{4}$ chimeric receptors bind CD200 but thereafter function like mCD200R2 with phosphorylation of the adaptor protein Dap12. 


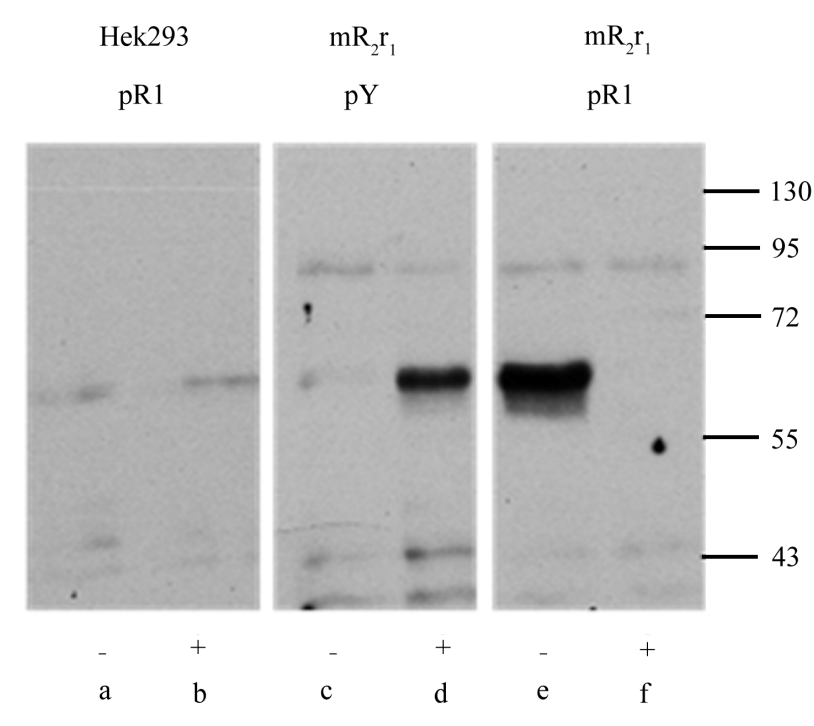

(A)

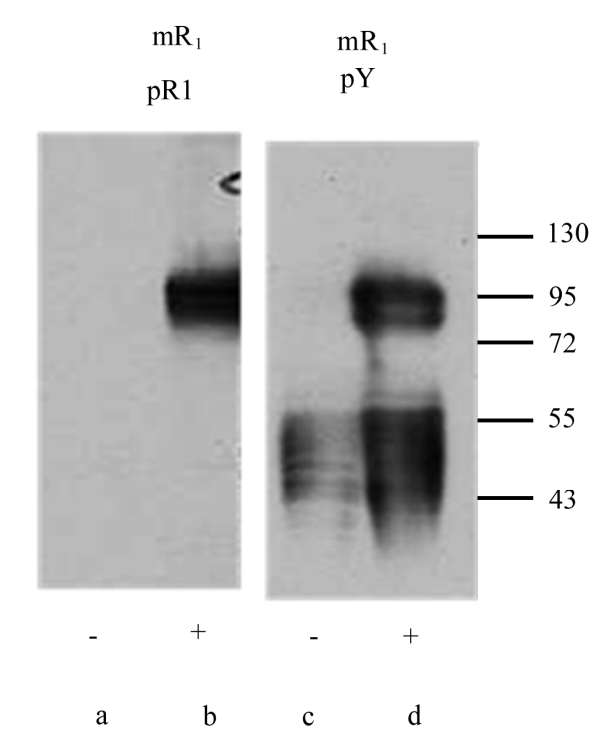

(B)

Figure 7. Functional activation of chimeric receptor $\mathrm{mR}_{2} \mathrm{r}_{1}$. Chimeric receptor $\mathrm{mR}_{2} \mathrm{r}_{1}$ (panel A) and receptor mR1 (panel B) were transiently transfected in Hek293 cells. 24 h post transfection, cells were incubated for $15 \mathrm{~min}$, at $37^{\circ} \mathrm{C}$ with $(+)$ or without $(-)$ supernatants from serum starved mouse CD200 expressing cells. Cell lysates were immunoprecipitated with antibody to tyrosine phosphorylated $\mathrm{mR} 1$ cytoplasmic region ( $\mathrm{pR} 1$ ) or commercial anti-phosphotyrosine antibody (pY) followed by western blotting using antibody 2A10 (panel B) or 5A4 (panel a). As controls, Hek293 cells were subjected to the same treatment as $\mathrm{mR}_{2} \mathrm{r}_{1}$.

\subsection{Evidence for Expression and Phoshorylation of Chimeric Receptor mR4r1}

As noted above, in the absence of anti-R4-specific mAbs, we have been unable to detect unequivocal expression of mR4 on the cell surface. Hek293 cells transfected with the chimeric receptor $\mathrm{mR}_{4} \mathrm{r}_{1}$ were stimulated with sodium pervanadate and subsequently immunoprecipitated with anti-phosphotyrosine antibody, followed by western gel analysis using antibody against the phosphorylated cytoplasmic tail of R1 as shown in Figure 8(b). Incubation of cells transfected with $\mathrm{mR}_{1} \mathrm{r}_{1}$ under similar conditions served as a positive control in these experiments. In preliminary studies we were unable to immunoprecipitate a specific phosphorylated product from $\mathrm{mR}_{4} \mathrm{r}_{1}$ transfected cells following incubation with mCD200 (data not shown), unlike the stimulation shown in Figure 7 with $\mathrm{mR}_{2} \mathrm{r}_{1}$ transfected cells. One interpretation of these data is that the CD200R4 receptor is not expressed functionally at the cell surface.

Interestingly, substitution of the TM and cytoplasmic region of $\mathrm{mR} 4$ with the corresponding region of $\mathrm{mR} 1$ resulted in a product that was fully glycosylated with molecular mass of $85 \mathrm{kDa}$ relative to $\mathrm{mR} 1$ which was detected at $\sim 90 \mathrm{kDa}$. Thus replacing the TM and CT region of $\mathrm{mR} 4$ with the corresponding regions of $\mathrm{mR} 1$ or with the $\mathrm{Fc}$ region of IgG2a, resulted in a highly glycosylated form of mR4 with its size in accordance with the number of $\mathrm{N}$-glycans in the extracellular region.

\section{DISCUSSION}

In the present study we have successfully generated monoclonals specific to $\mathrm{mR} 2$ and using these reagents have shown that $\mathrm{mR} 2$ is expressed on the cell surface. Cell surface expression of $\mathrm{mR} 2$ does not require the coexpression of adaptor molecule Dap12 in either Hek293 or CHOK cells. Furthermore, the presence of a C-terminal V5 tag on mR2 (i.e. mR2V5) did not affect its cell surface expression and immunoreactivity with the five anti-mR2 monoclonals described, two of which were able to detect mR2 and mR2V5 in cell lysates by westerns. In contrast, an antibody specific to $\mathrm{mR} 1$ has not, to our knowledge, been similarly defined. Rigorous tests of both our own anti-mR1 monoclonal (2A10) and a commercial anti-mR1 antibody (Serotec) showed these also recognized cell surface $\mathrm{mR} 2$ (and $\mathrm{mR} 2 \mathrm{~V} 5$ ). Unlike the commercial anti-CD200R1 reagent, 2A10 also bound to $\mathrm{mR} 1$ on western gels and in immunoprecipitation experiments.

Using antibodies specific to $\mathrm{mR} 2$, we have failed to detect heterodimers from cells expressing both $\mathrm{mR} 1$ and $\mathrm{mR} 2$. This makes it unlikely that multiple heterodimeric CD200Rs interact on individual cells following expression of more than one CD200R in any given cell.

$5 / 17$ monoclonals derived from immunization with $\mathrm{mR} 2 \mathrm{Fc}$ were specific for $\mathrm{mR} 2$. Anti-mR2 monoclonals 


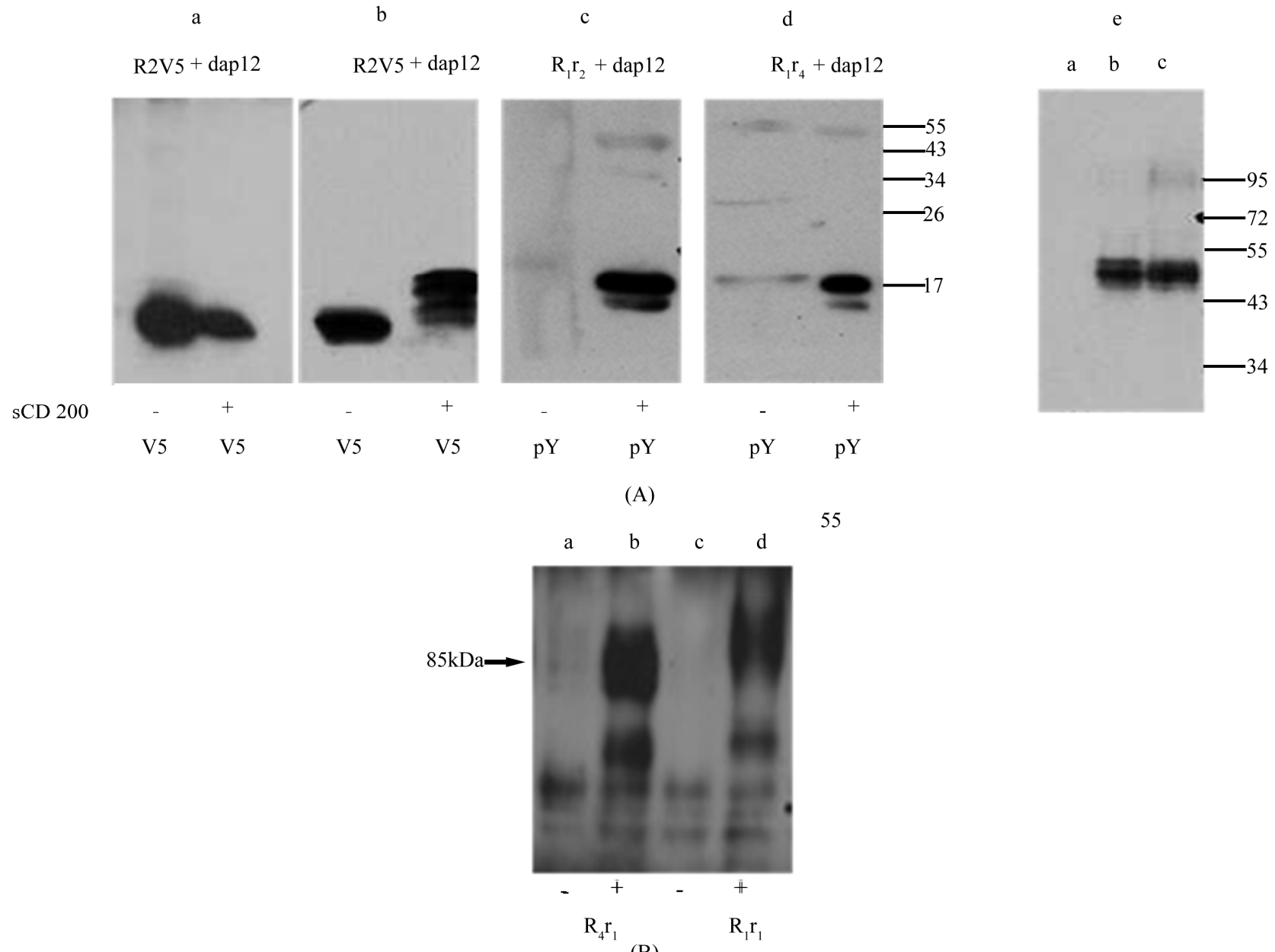

(B)

Figure 8. Functional activation of chimeric receptor $m R_{1} r_{2}$ and $m R_{1} r_{4}$. (A) Hek293 cells were transiently co-transfected with mdap12 and receptors $m R 4 V 5, m R 2 V 5$, chimeric receptors $m_{1} r_{2} / m_{1} r_{4} .24$ h post transfection, cells were stimulated by incubating for $15 \mathrm{~min}$, at $37^{\circ} \mathrm{C}$ with $(+)$ or without $(-)$ supernatants from serum starved mouse CD200 expressing cells. Panel a and b: Cell lysates, were immunoprecipitated with anti-V5 and western blotted using antibody to mDap12. Panel c and d: Cell lysates were immunoprecipitated with anti-phosphotyrosine antibody (anti-pY) and western blotted using antibody to mDap12. Panel e: Hek293 cell lysates (a), $\left[\mathrm{mR}_{1} \mathrm{r}_{2}+\right.$ Dap12] lysates (b) and [ $\mathrm{mR}_{1} \mathrm{r}_{4}+$ Dap12] lysates (c) were subjected to SDS/PAGE and western blotting using antibody $2 \mathrm{~A} 10$; (B) Data shows a western gel from cell lysates of $\mathrm{mR}_{4} \mathrm{r}_{1}$ (lanes a, b) and $\mathrm{mR}_{1} \mathrm{r}_{1}$ (lanes c,d) transfected cells immunoprecipitated with anti-phosphotyrosine antibody followed by western using antibody against the phosphosphorylated cytoplasmic tail of $\mathrm{mR} 1 .+/-$ represents incubation of transfected cells with or without pervanadate for $10 \mathrm{~min}$ at $37^{\circ} \mathrm{C}$.

$1 \mathrm{D} 2$ and $6 \mathrm{C} 10$ were also able to recognize cell surface $\mathrm{mR} 1$, which is not surprising since $\mathrm{mR} 1$ and $\mathrm{mR} 2$ show $\sim 84 \%$ sequence homology in their extracellular region. We have to date, as noted earlier, been unable to generate anti-R4 specific reagents using the approach successful in generating anti R1/R2 mAbs.

The presence of N-linked glycans on rat CD200R1 has been demonstrated by Wright et al. [3] with a drop in molecular mass from 90 to $25 \mathrm{kDa}$ following PNGaseF treatment of rat $\mathrm{R} 1$, indicating a content of $\sim 70 \%$ by weight of carbohydrate. In the studies reported above we confirmed that the extracellular region of all 4 mouse CD200Rs fused to $\mathrm{Fc}$ are glycosylated and the molecular weights of the molecules were dictated by the number of
$\mathrm{N}$-glycans with $\mathrm{mR} 1 \mathrm{Fc}$ at molecular mass $98 \mathrm{kDa}$, $\mathrm{mR} 4 \mathrm{Fc}$ at $95 \mathrm{kDa}, \mathrm{mR} 2 \mathrm{Fc}$ at $70 \mathrm{kDa}$ and $\mathrm{mR} 3 \mathrm{Fc}$ at 65 $\mathrm{kDa}$.

Interestingly, western blots of cell lysates from mR4V5 transfected cells showed a significantly lower molecular mass product compared to mR1 (48 $\mathrm{kDa}$ vs 90 $\mathrm{kDa}$ and experiments using tunicamycin also suggested that glycosylation in mR4V5 was reduced by more than $50 \%$ compared to $\mathrm{mR} 1$. Since $\mathrm{mR} 1$ and $\mathrm{mR} 4$ share the greatest homology in their extracellular region and contain similar number of $\mathrm{N}$-glycans, this unexpected reduction in the molecular weight of mR4V5 was taken to infer that the TM and CT region of $\mathrm{mR} 4$ may regulate the degree of glycosylation. We therefore explored the effect 
of switching carboxy terminal domains between the receptors on CD200R glycosylation and interaction with CD200 using anti-R1 and anti-R2 specific antibodies.

Substitution of the TM and CT region of $\mathrm{mR} 1$ and $\mathrm{mR} 2$ with that of $\mathrm{mR} 4$ significantly reduced glycosylation of the chimeric receptors $\mathrm{mR}_{1} \mathrm{r}_{4}$ and $\mathrm{mR}_{2} \mathrm{r}_{4}$ (Figure 5(c) and Figure 6(b)). Replacing the TM and CT region of $\mathrm{mR} 1$ with that of $\mathrm{mR} 2$ also caused a similar drop in molecular mass of the chimeric receptor $\mathrm{mR}_{1} \mathrm{r}_{2}$ (Figure 5(a)). This in itself was not surprising given that the TM and $\mathrm{CT}$ regions of $\mathrm{mR} 2$ and $\mathrm{mR} 4$ are conserved except for a few amino acids. In contrast to these data, however, substitution of the TM and $\mathrm{CT}$ region of $\mathrm{mR} 2$ with that of $\mathrm{mR} 1$ did not result in reduced glycosylation of the chimeric receptor $\mathrm{mR}_{2} \mathrm{r}_{1}$, inferring that the reduction of glycosylation was an effect regulated by the TM and CT region of $\mathrm{mR} 4 / \mathrm{mR} 2$ but not of $\mathrm{mR} 1$. Due to the lack of anti-mR4 antibodies, the chimeric receptor $\mathrm{mR}_{4} \mathrm{r}_{1}$ could not be studied in these experiments. However, in separate experiments, using an antibody specific to the phosphorylated cytoplasmic tail of $\mathrm{mR} 1$, we were able to show that when the TM and CT region of $\mathrm{mR} 4$ were replaced with the corresponding regions of $\mathrm{mR} 1$, the chimeric receptor $\mathrm{mR}_{4} \mathrm{r}_{1}$ (following activation with vanadate) was indeed glycosylated and appeared at the expected size of $85 \mathrm{kDa}$ (Figure 8(b)).

$\mathrm{N}$-glycosylation of eukaryotic membrane proteins is a co-translational event that occurs in the lumen of the endoplasmic reticulum. This process is catalyzed by a membrane associated oligosaccharyl transferase (OST) complex that transfers a preformed oligosaccharide $\left(\mathrm{Glc}_{3} \mathrm{Man}_{9} \mathrm{GlcNAc}_{2}\right)$ to an Asn side chain acceptor located within the sequence (Asn-X-Ser/Thr-). Although the presence of a consensus glycosylation site within the amino acid sequence of a membrane protein is suggestive of a glycoprotein, not all consensus sites are necessarily utilized. Sites must be disposed to the luminal side of the endoplasmic reticulum membrane to be glycosylated, and not all luminal sites may be suitable acceptors. A role for $\mathrm{N}$-glycosylation has been implicated in protein folding, regulation of cell surface expression and/or the half life of many proteins [21], though in many membrane proteins, N-linked oligosaccharides are not required for protein function [22-24].

It has been shown that acceptor sites for N-glycosylation must be spaced a minimum distance away from the membrane surface to be N-glycosylated [25], a constraint imposed by the relative proximity of the active site of the membrane-associated OST, and the residues near the ends of the transmembrane (TM) segments [26]. For more complex polytopic membrane proteins, N-glycosylation requires loops of a minimum size with the acceptor site spaced a minimum distance from the adjacent TM segments [27,28]. In a survey of 115 human single-span Type 1 membrane proteins a minimum distance of 10 residues from the bilayer was found to be necessary for successful N-glycosylation of acceptor sites preceding a membrane-spanning segment [29]. In a survey of proteins containing multiple extracytosolic N-glycosylation consensus sites, N-glycosylated extracytosolic loops were observed to have a minimum size of 33 residues [29], with smaller extracytosolic loops ( $<30$ residues) inefficient acceptors of oligosaccharide and thus poorly $\mathrm{N}$ glycosylated despite the presence of consensus $\mathrm{N}$ glycolsylation sites [30].

We observed a reduction in the glycosylation of the chimeric receptors $\mathrm{mR} 1 \mathrm{r} 2, \mathrm{mR} 1 \mathrm{r} 4$ and $\mathrm{mR} 2 \mathrm{r} 4$, which may reflect a similar restriction in accessibility of acceptor sites on the nascent polypeptide to the oligosaccharyl tranferase in the lumen of the endoplasmic reticulum. Relative to $\mathrm{mR} 4, \mathrm{mR} 1$ has a much longer cytoplasmic tail (63 amino acids in mR1 vs 9 amino acids for mR2) and we hypothesize that the extended cytoplasmic tail in mR1 may allow more flexibility in the ER for the nascent polypeptide to be efficiently glycosylated. Note then that the (presumed) glycosylation restraint imposed on the polypeptide chain of $\mathrm{mR} 4$ is relieved entirely by replacing it with the TM and $\mathrm{CT}$ region of $\mathrm{mR} 1$ or by replacing the TM and CT region with murine Fc.

In our activation experiments, we were able to show phosphorylation of mDap12 following incubation of cells expressing mR2V5 with mCD200. These results confirmed that mR2V5 was expressed on the cell surface and its binding to mCD200 led to phosphorylation of Dap12 a conclusion reached in earlier studies [11]. In similar experiments, we showed that the chimeric receptors $\mathrm{mR}_{1} \mathrm{r}_{2}$ and $\mathrm{mR}_{1} \mathrm{r}_{4}$ also bind the adaptor protein Dap12 and mimic mR2V5 functionally following stimulation with mCD200 (Figure 8(a)). Furthermore, using the antibody 2A10, we showed that the chimeric receptor $\mathrm{mR}_{2} \mathrm{r}_{1}$ mimics $\mathrm{mR} 1$ functionally following stimulation with $\mathrm{mCD} 200$. These data further support the suggestion we made earlier that in fact the alternate CD200Rs (besides CD200R1) do indeed bind CD200 in a functionally important manner $[1,11,13]$. In contrast to these observations, cells expressing mR4V5 bound Dap12, but Dap12 was not phosphorylated following stimulation with mCD200. Since CD200 has been shown to bind mR4 [10], this failure to observe mDap12 phosphorylation following mCD200 stimulation is taken to imply that mR4V5 does not appear on the cell surface and that it is likely a non-functional molecule. The failure of $\mathrm{mR}_{4} \mathrm{r}_{1}$ to bind mCD200 in our experiments may similarly indicate that $\mathrm{mR}_{4} \mathrm{r}_{1}$ is also not expressed on the cell surface. Alternatively, the chimeric receptor may have undergone a conformational change at the ligand binding site. 
Studies by Wright et al. and Hatherley et al. [2,9] using independent reagents to $\mathrm{mR} 1, \mathrm{mR} 3$ and $\mathrm{mR} 4$, showed expression of all three receptors on cell surface by flow cytometry following viral transduction in $\mathrm{BaF} 3$ cells stably expressing mDap12. The failure of this group also to demonstrate $\mathrm{mR} 4$ binding to a $\mathrm{CD} 200 \mathrm{Fc}$ fusion protein may again reflect the absence of cell surface expressed mR4. Our characterization of R4 has relied on detection of mR4V5 using a anti-V5 antibody. The possibility that the V5 tag interferes with $\mathrm{mR} 4$ glycosylation/surface expression is less of a concern given that mR2V5 was glycosylated and expressed on the cell surface and was not different in its properties from untagged $\mathrm{mR} 2$. However, we cannot entirely exclude this hypothesis.

Cell surface expression of the chimeric CD200 receptors $\mathrm{mR}_{1} \mathrm{r}_{2}, \mathrm{mR}_{1} \mathrm{r}_{4}$, and $\mathrm{mR}_{2} \mathrm{r}_{1}$ was detected by FACS using antibody $2 \mathrm{~A} 10$, whereas binding to $\mathrm{mR}_{2} \mathrm{r}_{4}$ was poor. No binding was observed with $\mathrm{mR}_{4} \mathrm{r}_{1}$ or mR4V5 transfected cells. Cumulatively, these results suggest that the 2A10 epitope in the extracellular region of the receptor is conserved between $\mathrm{mR} 1$ and $\mathrm{mR} 2$ and is maintained in the receptor chimeras. Since the epitope is lost in $\mathrm{mR}_{2} \mathrm{r}_{4}$ and mR4V5, both of which molecules have significantly reduced glycosylation, it may be that the 2A10 detects a conformational epitope dependent on glycosylation for its expression. Importantly the chimeric receptors $\mathrm{mR}_{1} \mathrm{r}_{2}$, $\mathrm{mR}_{1} \mathrm{r}_{4}$ and $\mathrm{mR}_{2} \mathrm{r}_{1}$ also maintained their binding to $\mathrm{mCD}$ $200 \mathrm{Fc}$. As judged by flow cytometry, $\mathrm{mR}_{2} \mathrm{r}_{1}$ but not $\mathrm{mR}_{2} \mathrm{r}_{4}$ showed immunoreactivity with $2 \mathrm{~A} 10$ as well as with all R2 specific monoclonals. In contrast, the chimeric receptor $\mathrm{mR}_{2} \mathrm{r}_{4}$ behaves like $\mathrm{mR} 4 \mathrm{~V} 5$ in that it does not appear on the cell surface; it does not bind mCD$200 \mathrm{Fc}$; and its expression can only be detected by westerns.

In summary, our data indicate that the TM and CT region of mCD200 receptors dictate their state of glycosylation which can further affect their structure and conformation. Despite extensive homology between the different CD200Rs, the distinctive TM and CT region in these receptors may thus contribute significant heterogeneity with respect to ligand binding. We have also provided further evidence to support the hypothesis that both CD200R1 and CD200R2 bind CD200 as ligand with functional consequences for downstream signaling. Furthermore, with the CD200Rs shared amino acid identity and conserved N-glycosylation sites, raising antiCD200R specific monoclonals will always remain a challenge.

\section{ACKNOWLEDGEMENTS}

This work was supported by grants from the Canadian Institute for
Health Research, MOP-221217

\section{REFERENCES}

[1] Gorczynski, R., Chen, Z., Kai, Y., Lee, L., Wong, S. and Marsden, P.A. (2004) CD200 is a ligand for all members of the CD200R family of immunoregulatory molecules. Journal of Immunology, 172, 7744-7749.

[2] Wright, G.J., Cherwinski, H., Foster-Cuevas, M., Brooke, G., Puklavec, M.J., Bigler, M., Song, Y., Jenmalm, M., Gorman, D., McClanahan, T., Liu, M.R., Brown, M.H., Sedgwick, J.D., Phillips, J.H. and Barclay, A.N. (2003) Characterization of the CD200 receptor family in mice and humans and their interactions with CD200. Journal of Immunology, 171, 3034-3046.

[3] Wright, G.J., Puklavec, M.J., Willis, A.C., Hoek, R.M., Sedgwick, J.D., Brown, M.H. and Barclay, A.N. (2000) Lymphoid/neuronal cell surface OX2 glycoprotein recognizes a novel receptor on macrophages implicated in the control of their function. Immunity, 13, 233-242. doi:10.1016/S1074-7613(00)00023-6

[4] Broderick, C., Hoek, R.M., Forrester, J.V., Liversidge, J., Sedgwick, J.D. and Dick, A.D. (2002) Constitutive retinal CD200 expression regulates resident microglia and activation state of inflammatory cells during experimental autoimmune uveoretinitis. American Journal of Pathology, 161, 1669-1677. doi:10.1016/S0002-9440(10)64444-6

[5] Gorczynski, R.M., Yu, K. and Clark, D. (2000) Receptor engagement on cells expressing a ligand for the toleranceinducing molecule $\mathrm{OX} 2$ induces an immunoregulatory population that inhibits alloreactivity in vitro and in vivo. Journal of Immunology, 165, 4854-4860.

[6] Hoek, R.M., Ruuls, S.R., Murphy, C.A., Wright, G.J., Goddard, R., Zurawski, S.M., Blom, B., Homola, M.E., Streit, W.J., Brown, M.H., Barclay, A.N. and Sedgwick, J.D. (2000) Down-regulation of the macrophage lineage through interaction with OX2 (CD200). Science, 290, 1768-1771. doi:10.1126/science.290.5497.1768

[7] Jenmalm, M.C., Cherwinski, H., Bowman, E.P., Phillips, J.H. and Sedgwick, J.D. (2006) Regulation of myeloid cell function through the CD200 receptor. Journal of Immunology, 176, 191-199.

[8] Snelgrove, R.J., Goulding, J., Didierlaurent, A.M., Lyonga, D., Vekaria, S., Edwards, L., Gwyer, E., Sedgwick, J.D., Barclay, A.N. and Hussell, T. (2008) A critical function for CD200 in lung immune homeostasis and the severity of influenza infection. Nature Immunology, 9, 1074 1083. doi:10.1038/ni.1637

[9] Hatherley, D., Cherwinski, H.M., Moshref, M. and Barclay, A.N. (2005) Recombinant CD200 protein does not bind activating proteins closely related to CD200 receptor. Journal of Immunology, 175, 2469-2474.

[10] Jiang, L. and Barclay, A.N. (2009) New assay to detect low-affinity interactions and characterization of leukocyte receptors for collagen including leukocyte-associated Iglike receptor-1 (LAIR-1). European Journal of Immunology, 39, 1167-1175. doi:10.1002/eji.200839188 
[11] Boudakov, I.Z.P. and Gorczynski, R. (2006) Mechanisms involved in suppression induced by CD200:CD200R interaction. Recent Research Developments in Immunology, 7, 9-24.

[12] Gorczynski, R.M., Chen, Z., Kai, Y., Wong, S. and Lee, L. (2004) Induction of tolerance-inducing antigen-presenting cells in bone marrow cultures in vitro using monoclonal antibodies to CD200R. Transplantation, 77, 1138-1144. doi:10.1097/01.TP.0000121773.18476.1C

[13] Gorczynski, R.M., Lee, L. and Boudakov, I. (2005) Augmented induction of CD4+CD25+ Treg using monoclonal antibodies to CD200R. Transplantation, 79, 1180-1183. doi:10.1097/01.TP.0000152118.51622.F9

[14] Mihrshahi, R., Barclay, A.N. and Brown, M.H. (2009) Essential roles for Dok2 and RasGAP in CD200 receptormediated regulation of human myeloid cells. Journal of Immunology, 183, 4879-4886. doi:10.4049/jimmunol.0901531

[15] Voehringer, D., Rosen, D.B., Lanier, L.L. and Locksley, R.M. (2004) CD200 receptor family members represent novel DAP12-associated activating receptors on basophils and mast cells. The Journal of Biological Chemistry, 279, 54117-54123. doi:10.1074/jbc.M406997200

[16] Zhang, S., Cherwinski, H., Sedgwick, J.D. and Phillips, J.H. (2004) Molecular mechanisms of CD200 inhibition of mast cell activation. Journal of Immunology, 173, 67866793.

[17] Gum Jr., J.R. (1992) Mucin genes and the proteins they encode: Structure, diversity, and regulation. American Journal of Respiratory and Critical Care Medicine, 7, 557-564.

[18] Preston, S., Wright, G.J., Starr, K., Barclay, A.N. and Brown, M.H. (1997) The leukocyte/neuron cell surface antigen OX2 binds to a ligand on macrophages. European Journal of Immunology, 27, 1911-1918. doi:10.1002/eji.1830270814

[19] van der Merwe, P.A. and Barclay, A.N. (1994) Transient intercellular adhesion: The importance of weak proteinprotein interactions. Trends in Biochemical Sciences, 19, 354-358. doi:10.1016/0968-0004(94)90109-0

[20] Gorczynski, R.M., Chen, Z., Diao, J., Khatri, I., Wong, K., Yu, K. and Behnke, J. (2010) Breast cancer cell CD200 expression regulates immune response to EMT6 tumor cells in mice. Breast Cancer Research Treatment, 123, 405-415. doi:10.1007/s10549-009-0667-8

[21] Paulson, J.C. (1989) Glycoproteins: What are the sugar chains for? Trends in Biochemical Science, 14, 272-276. doi:10.1016/0968-0004(89)90062-5

[22] Casey, J.R., Pirraglia, C.A. and Reithmeier, R.A. (1992) Enzymatic deglycosylation of human Band 3, the anion transport protein of the erythrocyte membrane. Effect on protein structure and transport properties. The Journal of Biological Chemistry, 267, 11940-11948.

[23] Gregory, R.J., Rich, D.P., Cheng, S.H., Souza, D.W., Paul, S., Manavalan, P., Anderson, M.P., Welsh, M.J. and Smith, A.E. (1991) Maturation and function of cystic fibrosis transmembrane conductance regulator variants bearing mutations in putative nucleotide-binding domains 1 and 2 . Molecular Cell Biology, 11, 3886-3893.

[24] Hryshko, L.V., Nicoll, D.A., Weiss, J.N. and Philipson, K.D. (1993) Biosynthesis and initial processing of the cardiac sarcolemmal $\mathrm{Na}(+)-\mathrm{Ca}^{2+}$ exchanger. Biochimica et Biophysica Acta (BBA), 1151, 35-42. doi:10.1016/0005-2736(93)90068-B

[25] Nilsson, I.M. and von Heijne, G. (1993) Determination of the distance between the oligosaccharyl transferase active site and the endoplasmic reticulum membrane. The Journal of Biological Chemistry, 268, 5798-5801.

[26] Killian, J.A. and von Heijne, G. (2000) How proteins adapt to a membrane-water interface. Trends in Biochemical Sciences, 25, 429-434. doi:10.1016/S0968-0004(00)01626-1

[27] Popov, M., Li, J. and Reithmeier, R.A. (1999) Transmembrane folding of the human erythrocyte anion exchanger (AE1, Band 3) determined by scanning and insertional N-glycosylation mutagenesis. Biochemical Journal, 339, 269-279. doi:10.1042/0264-6021:3390269

[28] Popov, M., Tam, L.Y., Li, J. and Reithmeier, R.A. (1997) Mapping the ends of transmembrane segments in a polytopic membrane protein. Scanning N-glycosylation mutagenesis of extracytosolic loops in the anion exchanger, band 3. The Journal of Biological Chemistry, 272, 1832518332. doi:10.1074/jbc.272.29.18325

[29] Landolt-Marticorena, C. and Reithmeier, R.A. (1994) Asparagine-linked oligosaccharides are localized to single extracytosolic segments in multi-span membrane glycolproteins. Biochemical Journal, 302, 253-260.

[30] Preston, G.M., Jung, J.S., Guggino, W.B. and Agre, P. (1994) Membrane topology of aquaporin CHIP. Analysis of functional epitope-scanning mutants by vectorial proteolysis. The Journal of Biological Chemistry, 269, 16681673 .

\section{ABBREVIATIONS}

CT: Cytoplasmic;

FACS: Flow cytometry analyses;

Fc: Fc domain of mouse IgG2a; mR1: Mouse CD200 receptor 1; mR2: Mouse CD200 receptor 2;
mR4: Mouse CD200 receptor 4; mDap12: Mouse adaptor protein Dap12; TM: Trans membrane; $\mathrm{mR}_{1} \mathrm{r}_{1}$ : Mouse CD200 receptor 1 ; $\mathrm{mR}_{2} \mathrm{r}_{2}$ : Mouse CD200 receptor 2. 


\section{SUPPLEMENTARY}

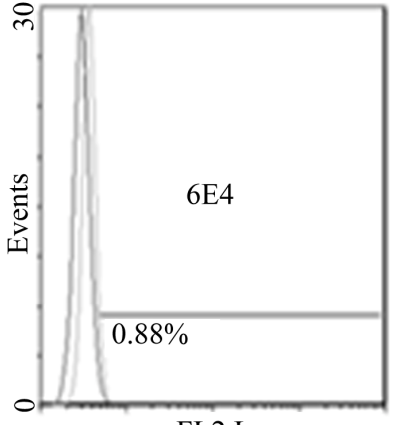

FL2 Log

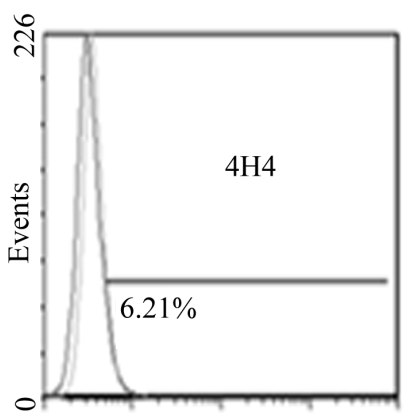

FL2 Log
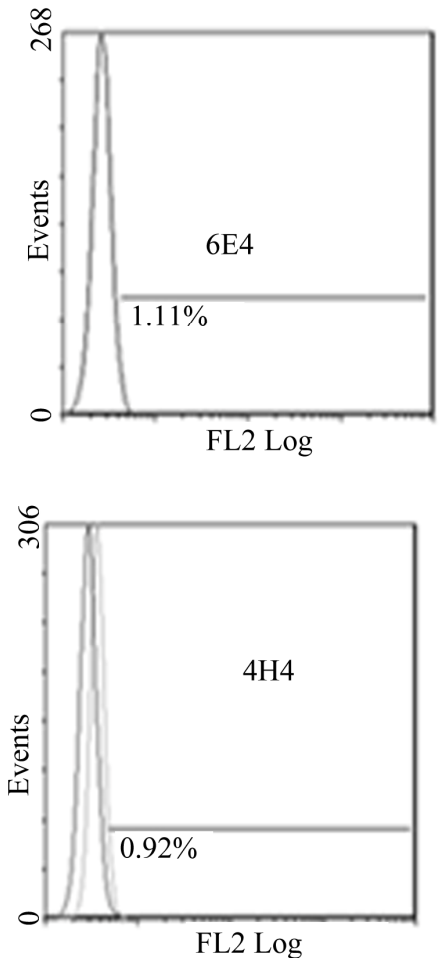
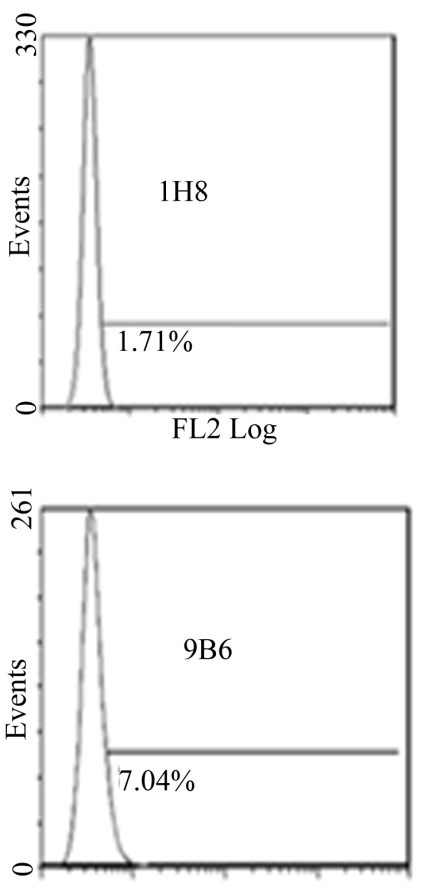

FL2 Log

(A)
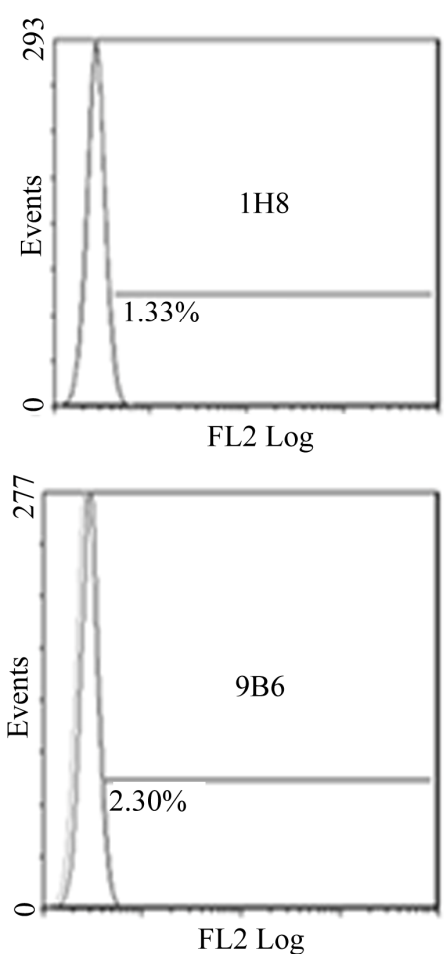

(B)

Figure 1. Anti-mR2 monoclonals do not recognize cells transfected with mR1his or mR4V5. Flow cytometery data for Hek293 cells stably transfected with mR1his (A) or mR4V5 (B). Cells were immunostained with anti-R2 monoclonals 6E4, 1H8, 4H4 and 9B6. 


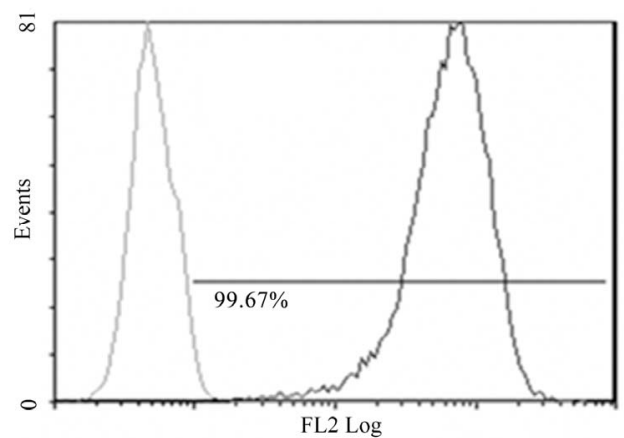

(A)

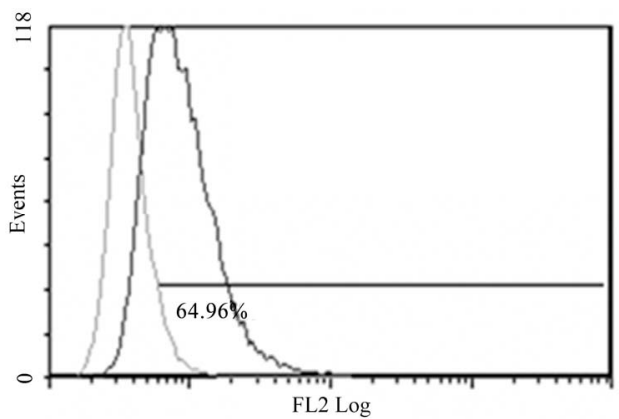

(B)

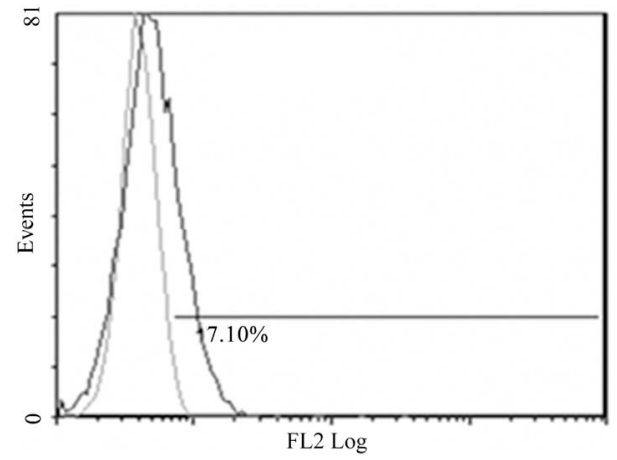

(C)

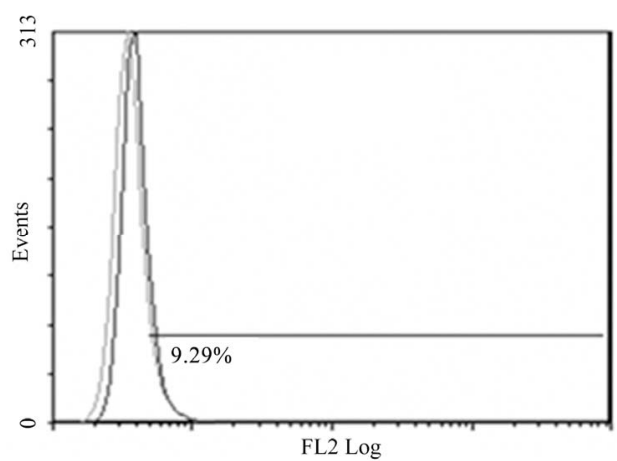

(D)

Figure 2. Anti-mR1 monoclonals recognize cells transfected with mR2V5 but not mR4V5. Flow cytometry data of Hek293 cells stably transfected with mR2V5 (A) and (B) or transiently transfected with mR4V5 (C) and (D) were immunostained with anti-R1 monoclonal 2A10 (A) and (C), or commercial ant-R1 antibody (B) and (D). 


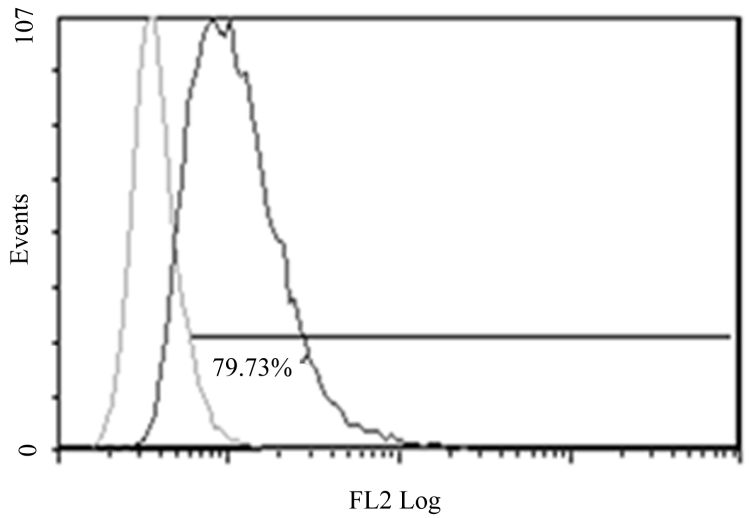

(A)

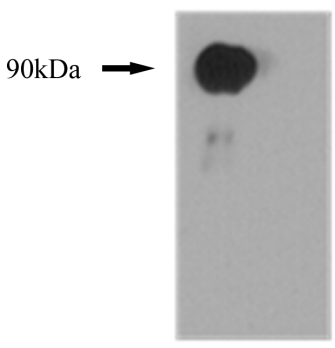

$2 \mathrm{~A} 10$

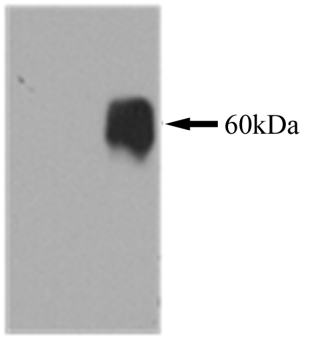

anti-V5

(B)

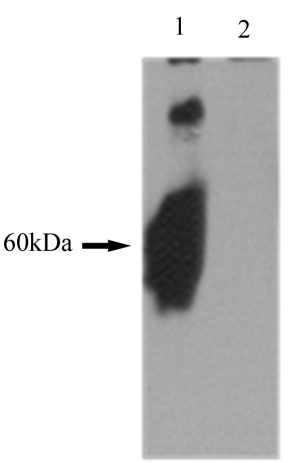

$5 \mathrm{~A} 4$

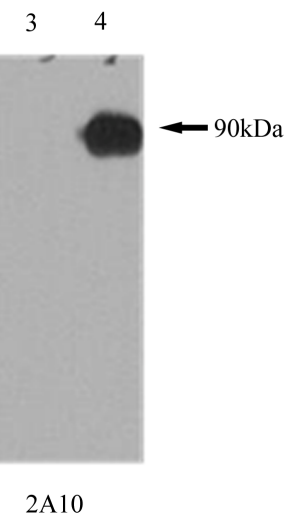

(D)

Figure 3. Lack of heterodimerization between $\mathrm{mR} 1$ and $\mathrm{mR} 2 \mathrm{~V} 5$. Stably transfected $\mathrm{mR} 1$ cells were transiently transfected with $\mathrm{mR} 2 \mathrm{~V} 5$ and $24 \mathrm{~h}$ post transfection stained with anti-R2 specific antibody $4 \mathrm{H} 4$ in FACS to confirm the expression of mR2V5 at the cell surface (A). Dual transfected cells were lysed and subjected to SDS/PAGE \& western blotting using anti-R1 (2A10)/anti-V5 antibody (B), or were immunoprecipitated with anti-V5 antibody (C \& D). Immunoprecipitates were analyzed using anti-R2 monoclonal antibody 5A4 (C, lane 1) or anti-mR1 monoclonal 2A10 (d lane 3). (lane 2 (C) represents immunoprecipitates from mock transfected cells, whereas (lane 4 (D) represents mR1 cell lysates (as control). 

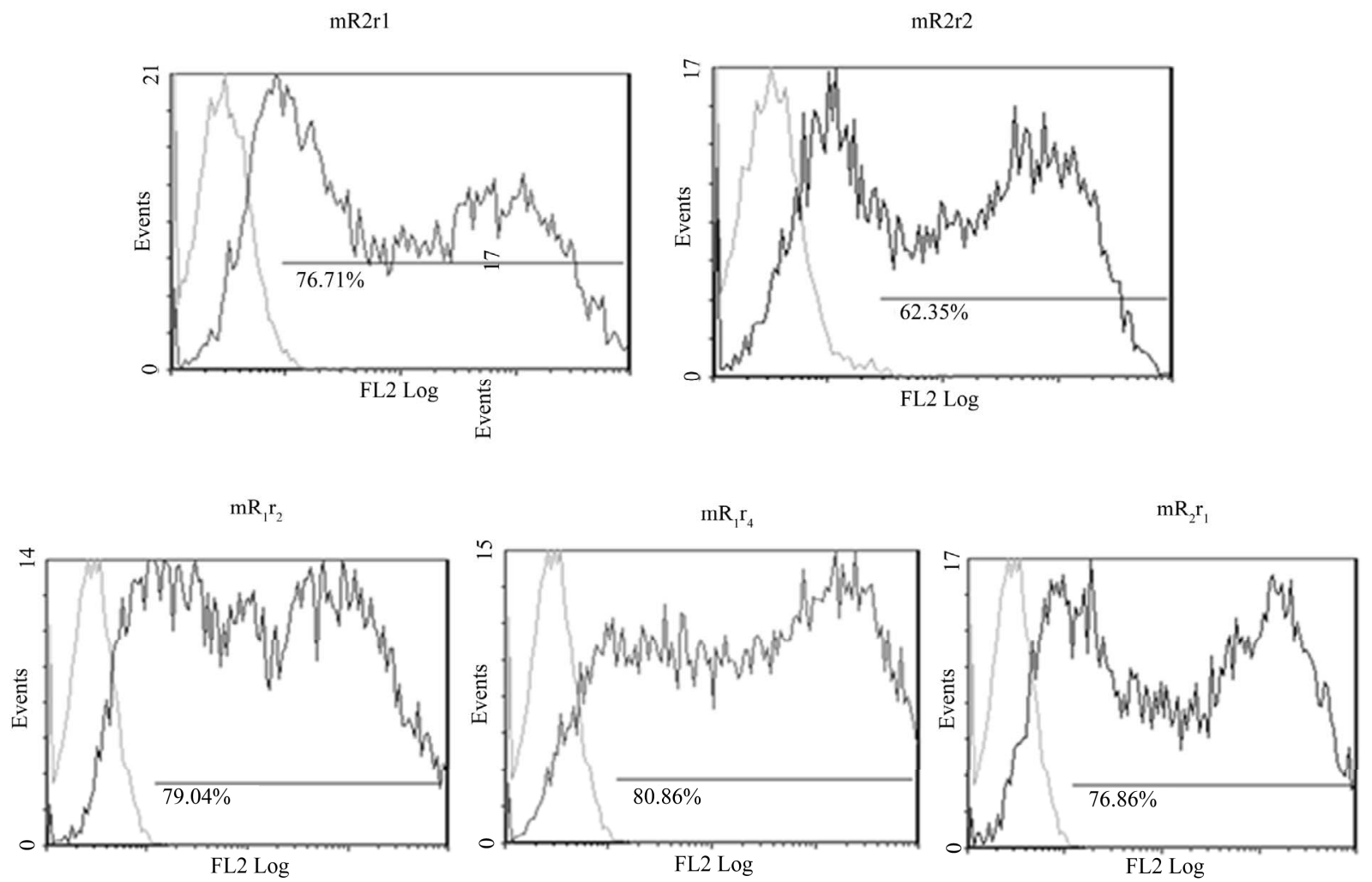

(A)
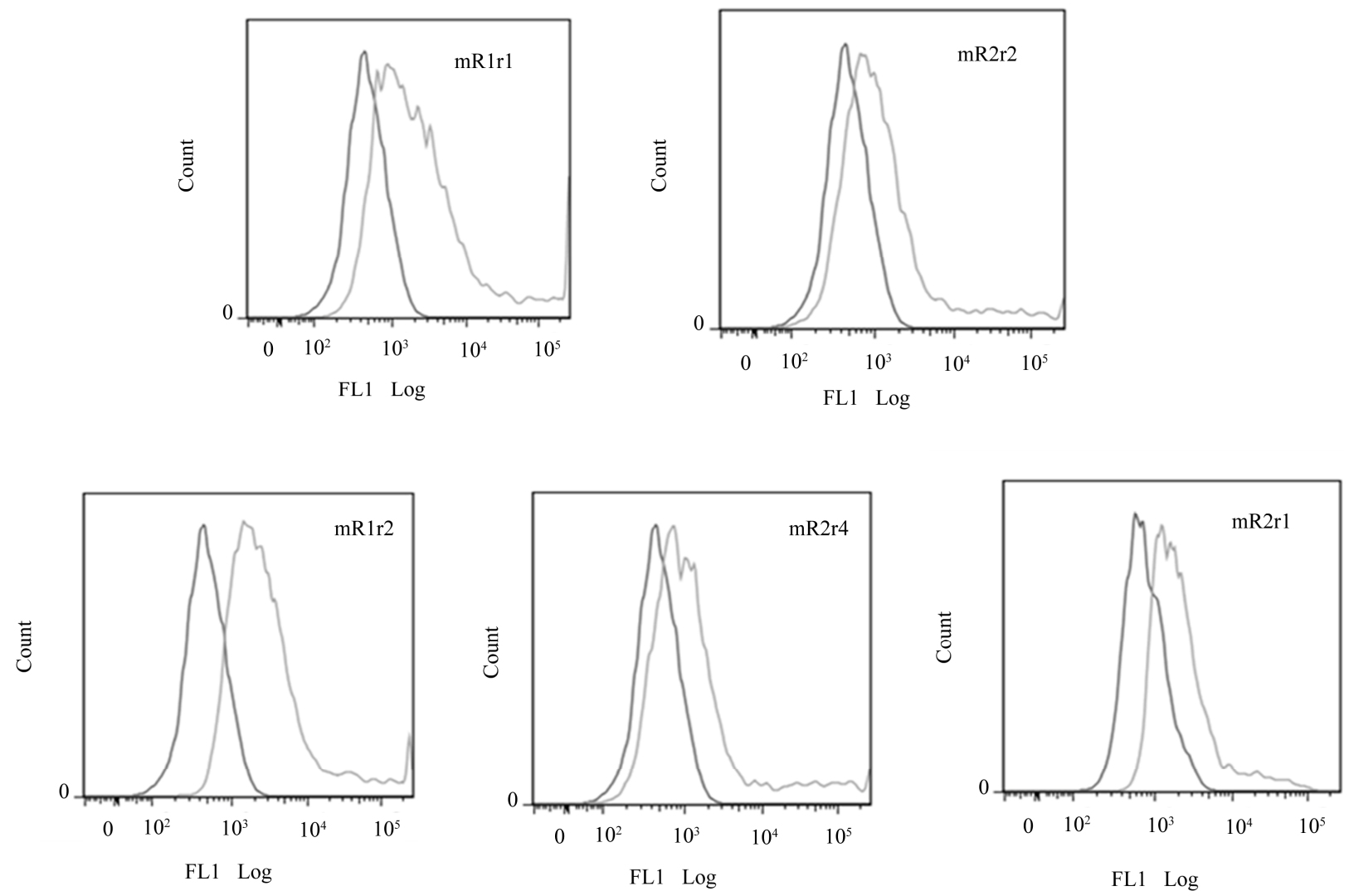

(B) 
(a) $m R_{2} r_{1}$ expression
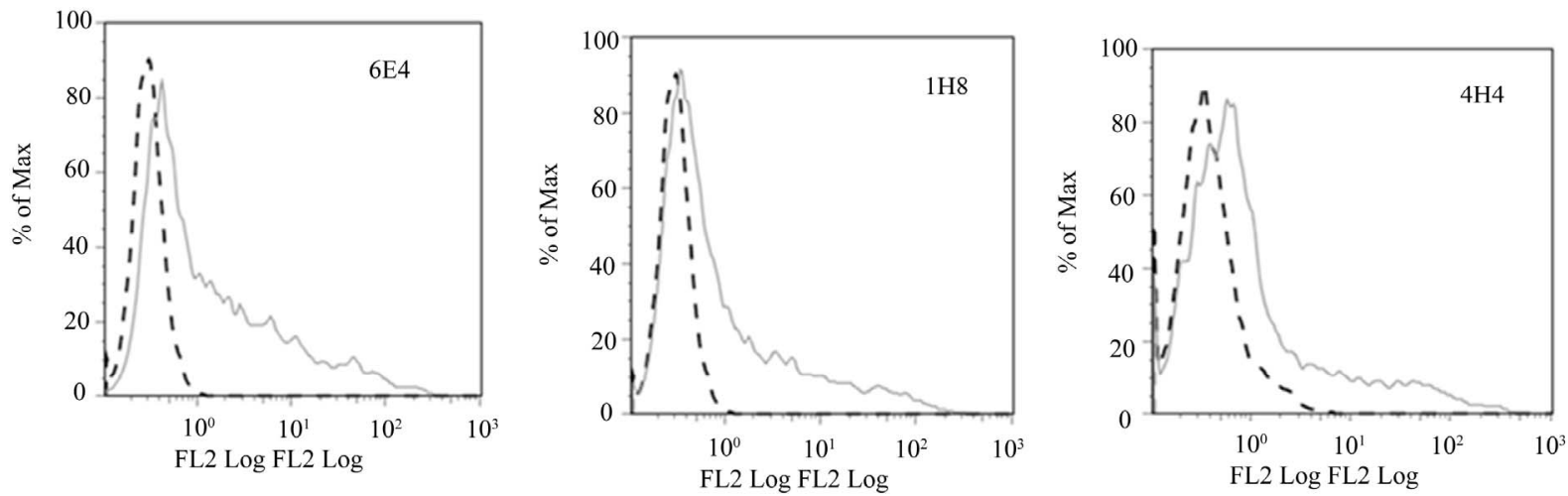

(b) $\mathrm{mR}_{2} \mathrm{r}_{4}$ expression
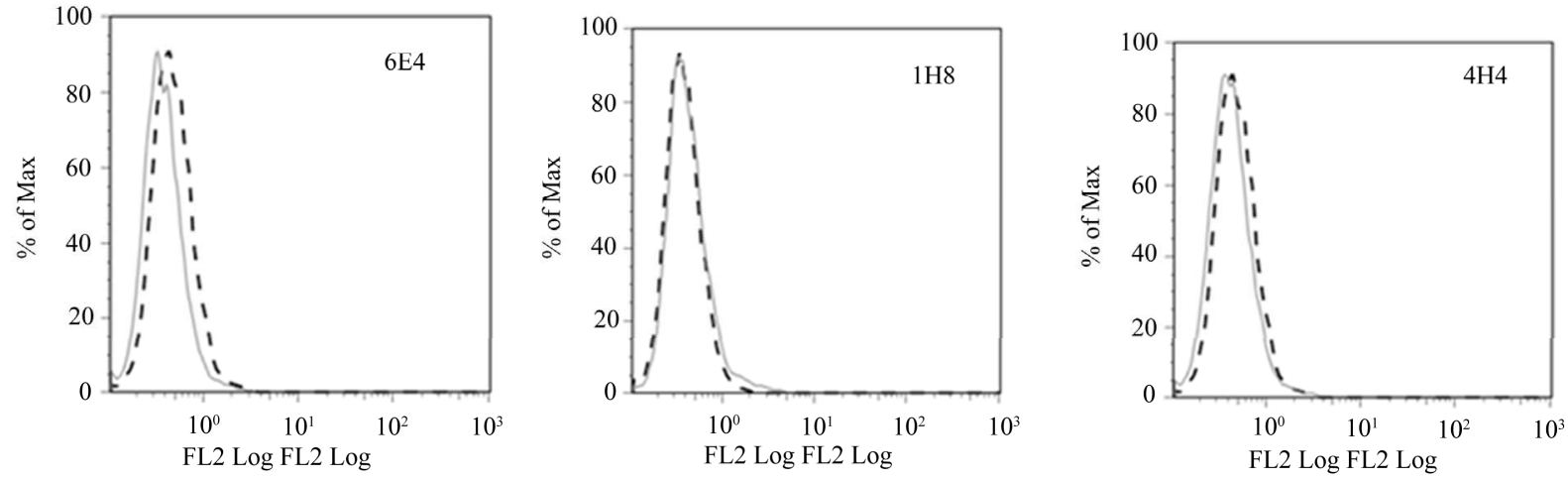

(C)

Figure 4. Expression of chimeric receptors in Hek293 and their binding to MCD200Fc. (A) Flow cytometry data of transiently transfected $\mathrm{mR}_{1} \mathrm{r}_{1}, \mathrm{mR}_{2} \mathrm{r}_{2}, \mathrm{mR}_{1} \mathrm{r}_{2}, \mathrm{mR}_{1} \mathrm{r}_{4}$ and $\mathrm{mR}_{2} \mathrm{r}_{1}$ cells immunostained with anti-R1 antibody $2 \mathrm{~A} 10$ (panel a); (B) Binding of mCD200Fc to transiently transfected $\mathrm{mR}_{1} \mathrm{r}_{1}, \mathrm{mR}_{2} \mathrm{r}_{2}, \mathrm{mR}_{1} \mathrm{r}_{2}, \mathrm{mR}_{1} \mathrm{r}_{4}$ and $\mathrm{mR}_{2} \mathrm{r}_{1}$ cells was assessed by incubating transfected cells with $5 \mu \mathrm{g} / \mathrm{ml}$ $\mathrm{mCD} 200 \mathrm{Fc}$ for $15 \mathrm{mins}$ at $37^{\circ} \mathrm{C}$, followed by staining with FITC labeled anti-mouse IgG (Fab) fragment. Binding of mouse Fc (5 $\mu \mathrm{g} / \mathrm{ml}$ ) to transiently transfected cells was used as the negative control in these experiments; (C) Flow cytometry data of Hek293 cells transiently transfected with $\mathrm{mR}_{2} \mathrm{r}_{1}$ and immunostained with anti-R2 monoclonals antibodies 6E4, 1H8 and 4H4 (panel a). Flow cytometry data of Hek293 cells transiently transfected with $\mathrm{mR}_{2} \mathrm{r}_{4}$ and immunostained with anti-R2 monoclonal antibodies $6 \mathrm{E} 4$, 1H8 and $4 \mathrm{H} 4$ (panel b). 